\title{
Removal of Erythrosine B dye from water effluents using crop waste pumpkin seed hulls as adsorbent
}

\author{
Laura Carmen Apostol ${ }^{\mathrm{a}, \mathrm{b}}$, Cristina Ghinea ${ }^{\mathrm{a}, \mathrm{b}}$, Madalena Alves ${ }^{\mathrm{c}}$, Maria Gavrilescu ${ }^{\mathrm{a}, \mathrm{d}, *}$ \\ ${ }^{a}$ Faculty of Chemical Engineering and Environmental Protection, Department of Environmental Engineering and Management, \\ "Gheorghe Asachi" Technical University of Iaşi, 73 Prof. Dr. Docent Dimitrie Mangeron Str., 700050 Iaşi, Romania, \\ Tel.+40 232278680, ext.2137; email: mgav@tuiasi.ro (M. Gavrilescu) \\ ${ }^{b}$ Faculty of Food Engineering, "Stefan cel Mare" University of Suceava, 13 University Street, Suceava, Romania \\ ${ }^{c}$ Department of Biological Engineering, University of Minho, Campus de Gualtar, 4710-057 Braga, Portugal \\ ${ }^{d}$ Academy of Romanian Scientists, 54 Splaiul Independentei, RO-050094 Bucharest, Romania
}

Received 22 August 2015; Accepted 11 December 2015

\begin{abstract}
Erythrosine B is widely used for coloring in various applications, especially in the food industry, despite its already proved toxicity and carcinogenicity. The agrowaste pumpkin seed hulls were applied as potential adsorbent for the removal of Erythrosine from aqueous solutions. Adsorption mechanism and kinetics were analyzed for design purposes. The seed hulls were characterized by specific techniques before and after dye retention. It was found that the attachment of Erythrosine B molecules on adsorbent surface may be attributed to the interactions between carboxyl and/or carbonyl groups of both dye and agrowaste wall components. A univariate approach followed by a factorial design was applied to study and analyze the experimental results as well as to estimate the combined effects of the process factors on the removal efficiency and dye uptake. Adsorption mechanism may be predominantly due to intraparticle diffusion, dependent on pore size. The four equilibrium models applied fitted the data well; the maximum adsorption capacity for Erythrosine was $16.4 \mathrm{mg} / \mathrm{g}$. The results showed that adsorbent is effective for Erythrosine B removal for a large concentration range in aqueous solutions $(5-400 \mathrm{mg} / \mathrm{L})$ in batch systems.
\end{abstract}

Keywords: Agrowaste; ANOVA; Food dye; Kinetics; Pumpkin seed hull; Adsorption mechanism; Thermodynamics

\section{Introduction}

The environmental pollution continues to be a problem that becomes acute when the pollutants display persistence and refractory character. This is the case of some synthetic dyes, specifically those belonging to the xanthene class. The interest for xanthene compounds has been stimulated due to their wide

*Corresponding author. range of applications as biological stains, sensitizers, tracing agents, laser dyes, and food dyes, although some of them proved to be toxic, both during the direct use and as dissolved compound in aqueous effluents.

Erythrosine B (CI 45,430) is a well-known and important representative of the xanthene dye class, widely used in practical applications for preparations coloring in food industry (sweets creams, dragees

1944-3994/1944-3986 @ 2015 Balaban Desalination Publications. All rights reserved. 
coatings, ice cream, cake-decorating gels, glace and tinned cherries, sausages, meat), cosmetic and pharmaceutical industry (pills coverage, syrups, toothpaste, lipstick, make up products, bath and shower products, hair-care products including sprays and conditioners, shampoos, deodorants, fragrance products, soaps), despite its toxic and carcinogenic effects against animals and humans. A variety of studies were devoted to the assessment of the acute toxicity of Erythrosine B, some performed before GLP standards or the relevant OECD test guidelines had been established. The major efforts in this concern were initiated in the 1970s, while the US FDA had instituted a partial ban on erythrosine in 1990, based on studies which indicated that high doses can cause cancer in rats, in particular thyroid tumor formation. Other effects are associated with bronchoconstriction, sequential vascular response, elevation of protein-bound iodide, and chromosomal damage. In spite of these concerns, the fate of Erythosine B in the environment is less investigated, and there is a limited number of published data on its removal from aqueous effluents which contain dissolved erythrosine, difficult to be eliminated by conventional wastewater treatments [1-9].

While almost every industrial dyeing process involves a solution of dye, water-soluble reactive and acid dyes are the most problematic pollutants, as they tend to pass unaffected through conventional treatment systems [10-12]. Sorption process is often one of the effective methods to removes hazardous dyes from aqueous media [13-17]. The use of low-cost, easily obtained, highly efficient and eco-friendly adsorbents has been investigated as a sustainable alternative to the current expensive methods for dyes removal [3,4,18-20]. The environment offers biomaterials which can be used as adsorbents, to remove dyes contaminants from aqueous systems [12,21,22].

Different studies for the elimination of Erythrosine $B$ from aqueous solutions are based on degradation methods, when researchers found that the intermediates formed can be toxic [8,15,23-25]. Considering these aspects, adsorption can be a good alternative for Erythrosine B immobilization and removal, when lowcost and environmental friendly adsorbents are used, even though it does not result in chemical degradation of the pollutant $[1,5,12,25,26]$.

In this study the agrowaste pumpkin seed hulls (PSH) were used for the first time as a potential effective adsorbent for the removal of Erythrosine B from aqueous solutions. This adsorbent was chosen due to its availability in high amounts, as a crop waste. The advantage of using this type of material is twofold: first, it can act as an effective and economic adsorbent for solving the problem of color pollution, and second, an effective and useful exploitation mode of this agricultural waste is provided (instead of its burning or leaving on farmland, where it rots). This way, both environmental and agricultural sustainability can be addressed in a proficient and cost-effective manner.

Since the adsorption process is affected by a great number of parameters, preliminary experiments were carried out to find the most important factors effecting the adsorption of Erythrosine B on PSH. Batch experiments were conducted to study the influence of $\mathrm{pH}$ of initial solution, dye concentration, process temperature, adsorbent dose, and contact time on dye adsorption efficiency and uptake. In a first step, we applied an univariate approach, where one parameter varied, while the others are kept constant. In a second step, we considered the synergistic effect of the process variables on Erythrosine B uptake, as a consequence of their interactions using an experimental statistical design. A factorial design was applied to study and interpret the experimental results, which allowed us to screen variables, to estimate the joint effects of the operating parameters, such as: $\mathrm{pH}$; dose of $\mathrm{PSH}$ adsorbent $C_{\text {OPSH }}(\mathrm{g} / \mathrm{L})$; contact time $t$ ( $\left.\mathrm{min}\right)$; temperature $T$ $\left({ }^{\circ} \mathrm{C}\right)$; initial concentration of Erythrosine B in solution, $\mathrm{C}_{\text {OEry }}(\mathrm{mg} / \mathrm{L})$ on the magnitude of Erythrosine $\mathrm{B}$ uptake $q_{\exp }(\mathrm{mg} / \mathrm{g})$, from a minimum number of experiments.

The data obtained from Erythrosine B adsorption onto PSH were analyzed using four types of kinetic models and the four most used types of empirical isotherms models. The results were correlated with some thermodynamic parameters (free energy of adsorption $\left(\Delta G^{\circ}\right)$, enthalpy $\left(\Delta H^{\circ}\right)$, and entropy $\left(\Delta S^{\circ}\right)$. The adsorbent was characterized before and after Erythrosine B adsorption and a possible adsorption mechanism was proposed based on scanning electron microscopy (SEM) and Fourier transform infrared spectroscopy (FTIR) analyses, conducted for the validation of adsorption mechanism data.

\section{Experimental}

\subsection{Materials}

The acid dye used in this study, Erythrosine B (Ery B, CI 45,430) (Fig. 1), was purchased from SigmaAldrich (C.I. Acid Red 51, 45,430). A stock solution of $1,000 \mathrm{mg} / \mathrm{L}$ was prepared by dissolving an accurately weighed amount of Ery B in $500 \mathrm{~mL}$ distilled water. For the experimental assays, dilution of the stock was done to achieve the desired concentration, always when necessary.

The agrowaste used in the study was collected from a local farm. Pumpkin, Cucurbita pepo L. is an 


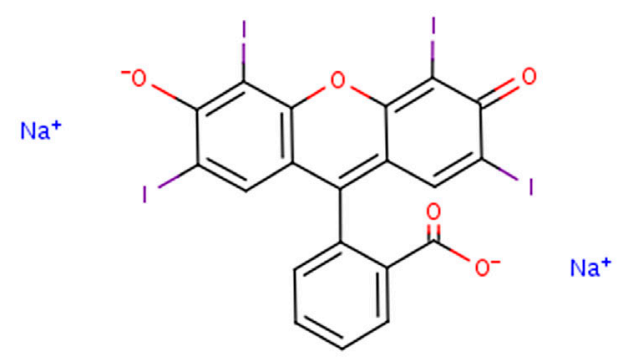

Fig. 1. Chemical structure of Erythrosine B.

herbaceous, monoecious, annual plant of the Cucurbitaceous family. Hull-less seed variety of pumpkin contains 5.49\% moisture and the dry residue shows high oil $(44.4 \%)$ and proteins $(32.59 \%)$ contents, $96 \%$ digestibility, which is interesting for food industry. Cellulose is the major unavailable carbohydrate, present in a concentration of $4.69 \%$, while the concentration of hemicelluloses and pectin are 4.80 and 2.7\%, respectively [27]. Pumpkin seeds were dehulled manually in the laboratory; in practice, the process is carried out by means of various types of machines. Before using as adsorbent, the waste was washed several times with distilled water to remove any adhering dirt and dried at $40^{\circ} \mathrm{C}$ for $24 \mathrm{~h}$. The dried sample was crushed using a Retsch GM 200 laboratory mill. No other chemical or physical treatments were used prior to adsorption experiments. Finally, they were sieved and classified. The particles size less than $3 \mathrm{~mm}$ of PSH were used in the experiments study. The adsorbent was stored in plastic boxes.

SEM analysis was carried out for the PSH, to study its surface texture before and after Ery B adsorption. Fourier transform infrared (FTIR) analyses were made in order to determine the functional groups involved in the adsorption process of Ery B on PSH.

The point of zero charge ( $\mathrm{pH}_{\mathrm{PZC}}$ ) describes the condition when the electrical charge density on a surface is zero. In the field of environmental science, it determines how easily a substrate is able to absorb potentially harmful ions [28]. The point of zero charge $\left(\mathrm{pH}_{\mathrm{PZC}}\right)$ of PSH was determined by immersion technique and potentiometric mass titrations (PMT) as was described by Fiol and Villaescusa [29]. Due to the low density of the studied materials compared to the hydr(oxides) used in the work of Bourikas et al. [30], vigorous agitation was needed to ensure homogenization of the suspension.

\subsection{Batch adsorption study}

Batch experiments were performed in 250-mL Erlenmayer flasks, containing $50 \mathrm{~mL}$ of Ery B solution at various concentrations $(10,20,40,60,80,100,150$, 200, 300, and $400 \mathrm{mg} / \mathrm{L}$ ) and different amounts of adsorbent (10, 20 and $30 \mathrm{~g} / \mathrm{L})$. The flasks were incubated at room temperature $\left(25 \pm 1^{\circ} \mathrm{C}\right)$ and $150 \mathrm{rpm}$ in an isothermal shaker (IKA KS 4,000 IC) for $24 \mathrm{~h}$, when dye removal reaches the equilibrium. All the experiments were carried out in duplicate at the natural $\mathrm{pH}$ of the solution ( $\mathrm{pH}$ 5.6). Factors affecting dye adsorption efficiency were investigated namely: initial dye concentration, adsorbent amount, $\mathrm{pH}$, temperature, and contact time.

\subsection{Desorption study}

After each adsorption cycle, the adsorbent was washed gently with distilled water to remove any unabsorbed dye. Different solutions were used for desorption tests: acids, bases, and organic solvents. Sulfuric acid $(0.2 \mathrm{M})$, hydrochloric acid $(0.2 \mathrm{M})$, acetic acid $(1 \mathrm{M})$, sodium chloride $(1 \mathrm{M})$, and sodium hydroxide adjusted at $\mathrm{pH} 10$ with distilled water were used to desorb $20 \mathrm{mg} / \mathrm{L}$ Erythrosine B; $50 \%$ acetone, $40 \%$ isopropanol, $40 \%$ ethanol, and distilled water $\mathrm{pH}$ 11 (adjusted with $\mathrm{NaOH}$ ), respectively were used to desorb $50 \mathrm{mg} / \mathrm{L}$ Ery B.

\subsection{Analysis methods and data processing}

The solutions containing different dye concentrations were analyzed spectrophotometrically (T60 UV-visible Spectrophotometer) at the maximum absorption wavelength of $524 \mathrm{~nm}$, which corresponds to the maximum absorption peak of the Ery B. Dye removal was monitored by measuring the absorbance of Ery B. Samples ( $3 \mathrm{~mL}$ ) were taken before mixing of the adsorbent with dye solution, then at different time intervals for the determination of residual dye concentration in solution. Samples were centrifuged at 6,000 rpm for $10 \mathrm{~min}$ using Mikro 220R centrifuge to separate the suspended adsorbent.

The characteristic parameters for each isotherm and kinetic model and related correlation coefficients have been determined using ORIGIN 8 PRO Software. The $\mathrm{pH}$ solution was measured using a Hanna $\mathrm{pH}$ meter provided with a combined glass electrode (Model Hanna HI1053B).The dye uptake per unit mass of adsorbent at the time $t,\left(q_{t}, \mathrm{mg} / \mathrm{g}\right)$ and at equilibrium $\left(q_{\mathrm{e}}, \mathrm{mg} / \mathrm{g}\right)$ was calculated using Eq. (1). The adsorption efficiency was calculated applying Eq. (2):

$q_{\exp }=\frac{C_{0 \text { Ery }}-C_{\mathrm{tEry}}}{m} \times V$ 
$R(\%)=\frac{C_{0 \text { Ery }}-C_{\mathrm{e}}}{C_{\mathrm{e}}} \times 100$

where $C_{0 \text { Ery }}$ is the initial dye concentration $(\mathrm{mg} / \mathrm{L})$; $C_{\mathrm{tEry}}$ and $C_{\mathrm{e}}$ are the concentrations of dye at time $t$ and at equilibrium ( $\mathrm{mg} / \mathrm{L}) ; m$ is the amount of dried adsorbent used ( $\mathrm{g}$ ); and $V$ is the volume of the solution (L).

Desorption efficiency was measured using Eq. (3):

$D(\%)=\frac{q_{0}-q_{\mathrm{d}}}{q_{0}} \times 100$

where $q_{0}$ is the amount of the Ery B sorbed onto PSH, $\mathrm{mg} / \mathrm{g} ; q_{\mathrm{d}}$ is the amount of Ery B in the solvent solution used for dye desorption.

\subsection{Statistical analysis}

In order to examine the joint effects of the experimental parameters on the process response, we used a factorial design of experiments, which allowed us to develop an analysis of variance and the fitting of the experimental response to that given by the regression model. The preliminary and univariate experiments showed that the following process variables are important: $\mathrm{pH},\left(x_{1}\right)$; adsorbent dose $\mathrm{C}_{\mathrm{OPSH}}, \mathrm{mg} / \mathrm{L}\left(x_{2}\right)$; contact time $t, \min \left(x_{3}\right)$; temperature $T,{ }^{\circ} \mathrm{C}\left(x_{4}\right)$; initial concentration of Ery B in solution $C_{0 \text { Ery }}, \mathrm{mg} / \mathrm{L}\left(x_{5}\right)$. Since we have more than 4 factors, a fractional factorial design, $2^{5-1}$ type was selected, which includes 16 experiments, with each factor at two levels [31]. The response of the system is given in terms of Erythrosine B uptake $q_{\exp }(\mathrm{mg} / \mathrm{g})$. In the first stage, we were seeking the representation of the process by an ideal model in the general form (Eq. (4)). To assess the importance of key variables, the model is further completed with terms of order $2, x_{i j}$ :

$y^{2}=\beta_{0} x_{0}+\beta_{1} x_{1}+\beta_{2} x_{2}+\beta_{3} x_{3}+\beta_{4} x_{4}+\beta_{5} x_{5}$

Minimum and maximum levels of each parameter are selected according to the preliminary experiments are shown in Table 1 . The results were analyzed with SPC for Excel and the leading effects and interactions among variables were determined.

\section{Results and discussion}

3.1. Characterization of pumpkin seeds hulls before and after dye adsorption

Fig. 2 shows the SEM micrographs (Leica Cambridge S360 Scanning Electron Microscope (SEM),
University of Minho, Guimarães, Portugal) of PSH samples before after dye adsorption. PSH has considerable numbers of heterogeneous large and medium pores where there is a good opportunity for dye to be cached and adsorbed. The images of dye-loaded adsorbent show that the surface was covered with dye molecules. Therefore, it is possible that the adsorption was carried out in monolayer, with a horizontal dye settlement.

Fourier transform infrared (FTIR) analysis of dye and adsorbent system were performed using a BOMEN MB 104 spectrometer, with a resolution of $4 \mathrm{~cm}^{-1}$ and a speed of 21 scans $\min ^{-1}$. The total number of scans was 16. As control, the mixtures of dye powder and adsorbent were also analyzed. The sample pellets were prepared in $\mathrm{KBr}$. The spectra ranged from 400 to $4,500 \mathrm{~cm}^{-1}$. FTIR analyses were carried out in order to determine the functional groups involved in the process of dye adsorption (Figs. 3(a) and (b)). A band at the range of 3,420$3,450 \mathrm{~cm}^{-1}$, corresponding to $\mathrm{OH}$ groups from phenol, carboxyl, and alcohol groups, and in the range of $2,300-2,900 \mathrm{~cm}^{-1}$, probably from $\mathrm{C}-\mathrm{H}$ groups, were observed for all the samples. The spectra of samples using PSH as adsorbent also suggest the involvement of some groups on the adsorption process (Figs. 3(a) and (b)). Three new peaks, at 1,227, 1,416 , and $1,506 \mathrm{~cm}^{-1}$, and some shifts of other peaks were observed in the FTIR spectra. The new peaks of Ery B-PSH used as adsorbent, may correspond to the assignments $\mathrm{C}-\mathrm{O}-\mathrm{H}\left(1,227 \mathrm{~cm}^{-1}\right), \mathrm{C}-\mathrm{O}$ $\left(416 \mathrm{~cm}^{-1}\right)$ and $\mathrm{C}=\mathrm{C}\left(1,506 \mathrm{~cm}^{-1}\right)$.

In Fig. 4(a) the data obtained using immersion techniques (IT) for the determination of the point zero charge (pHpzc) are plotted, which provides information on the surface charge of the adsorbent at a given $\mathrm{pH}$, while its knowledge offers information about the possible electrostatic interactions between adsorbent and various chemical species [29,30]. The experimental curves corresponding to PMT method technique are presented in Fig. 4(b). From the obtained curves for specific adsorbent masses, the pHpzc is identified as the common point of titrations curves for different masses converge [29]. A value of 6.2 was determined for pHpzc. The results indicated that the PSH surface is mostly acidic and this could be a favorable property for Ery $\mathrm{B}$ adsorption at $\mathrm{pH}$ around 6, when the adsorbent is positively charged. The difference between pHpzc determined using the two methods was around $0.5 \mathrm{pH}$ units. Therefore, the applied methods can be considered easy and appropriate technique to determine pHpzc of vegetable wastes. 
Table 1

Levels of the parameters which influence the Ery B uptake in the designed set of experiments

\begin{tabular}{lllll}
\hline Parameter & Coded symbol & -1 & 0 & 1 \\
\hline $\mathrm{pH}$ & $x_{1}$ & 5 & 7.5 & 10 \\
Sorbent dosage $\left(C_{\mathrm{OPSH}}, \mathrm{g} / \mathrm{L}\right)$ & $x_{2}$ & 2.5 & 26.25 & 50 \\
Time $(t, \mathrm{~min})$ & $x_{3}$ & 5 & $1,442.5$ & 2.5 \\
Temperature $\left(T,{ }^{\circ} \mathrm{C}\right)$ & $x_{4}$ & 20 & 35 & 23.75 \\
Initial concentration of Erythrosine $\left(C_{\text {OEry }}, \mathrm{mg} / \mathrm{L}\right)$ & $x_{5}$ & 5 & 52.5 & $1,437.5$ \\
\hline
\end{tabular}

(a)

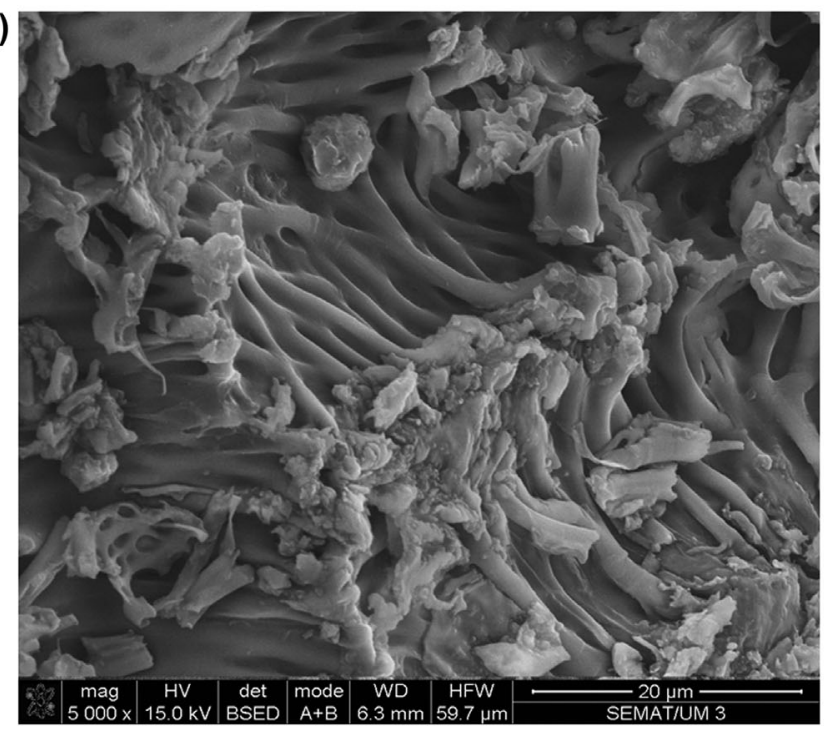

(b)

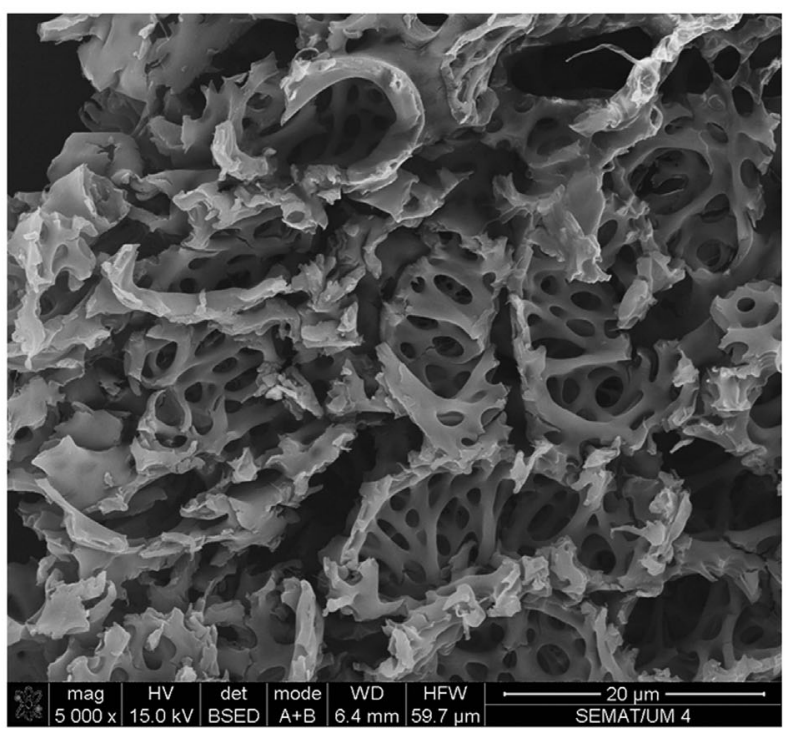

Fig. 2. SEM images of (a) fresh PSH and (b) PSH with Erythrosine B adsorbed.

\subsection{Factors affecting dye uptake and removal}

\subsubsection{Effect of $\mathrm{pH}$ on dye uptake}

The preliminary experimental data showed that the $\mathrm{pH}$ of the solution exerts a strong influence on the uptake of dyes molecules due to its influence on the surface properties of the adsorbent, as well as on ionization and dissociation of the dyes molecules. To analyze the effect of $\mathrm{pH}$ on the PSH adsorption capacity and process efficiency, experiments were carried out at different $\mathrm{pH}$ values of the initial solution varying from 4 to 10 (Fig. 5(a)).

Theoretically, when the electrostatic forces between the adsorbent surface and adsorbate ions are attractive, an increase in ionic strength will decrease the adsorption capacity [32]. The pKa value of Ery was established by Colar et al. [16] at 5.3 and the pHpzc of PSH was determined to be 6.2. The experimental data from this study did not follow this convention, as the adsorption of negatively charged dye molecules on positively charged component of $\mathrm{PSH}$ increased at
$0.81 \mathrm{mg} / \mathrm{g}$ with the decrease of $\mathrm{pH}$ until 5 . The minimum uptake of $0.4 \mathrm{mg} / \mathrm{g}$ Ery B was achieved at $\mathrm{pH}$ 10. For $\mathrm{pH}$ less than 5, Ery $\mathrm{B}$ in contact with the adsorbent reacts and the absorbance of the solution decreased very much due to the strong acidity of the medium that leads to dye precipitation [33]. As the functional groups of acid dyes are anionic in nature, they release negative charges when dissolved in water. Acid dyes have negative electrical structure of the chromophore group, thus the positively charged species of the dye can cause destabilization of negatively charged molecules by adsorption onto the surface of agrowaste [34]. This may be due to high electrostatic attraction between the positively charged surface of the adsorbent and anionic dye. The $\mathrm{COO}^{-}$groups present in Ery B play a major role in enhancing the dye adsorption process. As the initial $\mathrm{pH}$ increases, the number of negatively charged sites on the adsorbent surface increases and the number of positively charged sites decreases [35]. In acidic conditions, the surface of the adsorbent is positively charged due to 

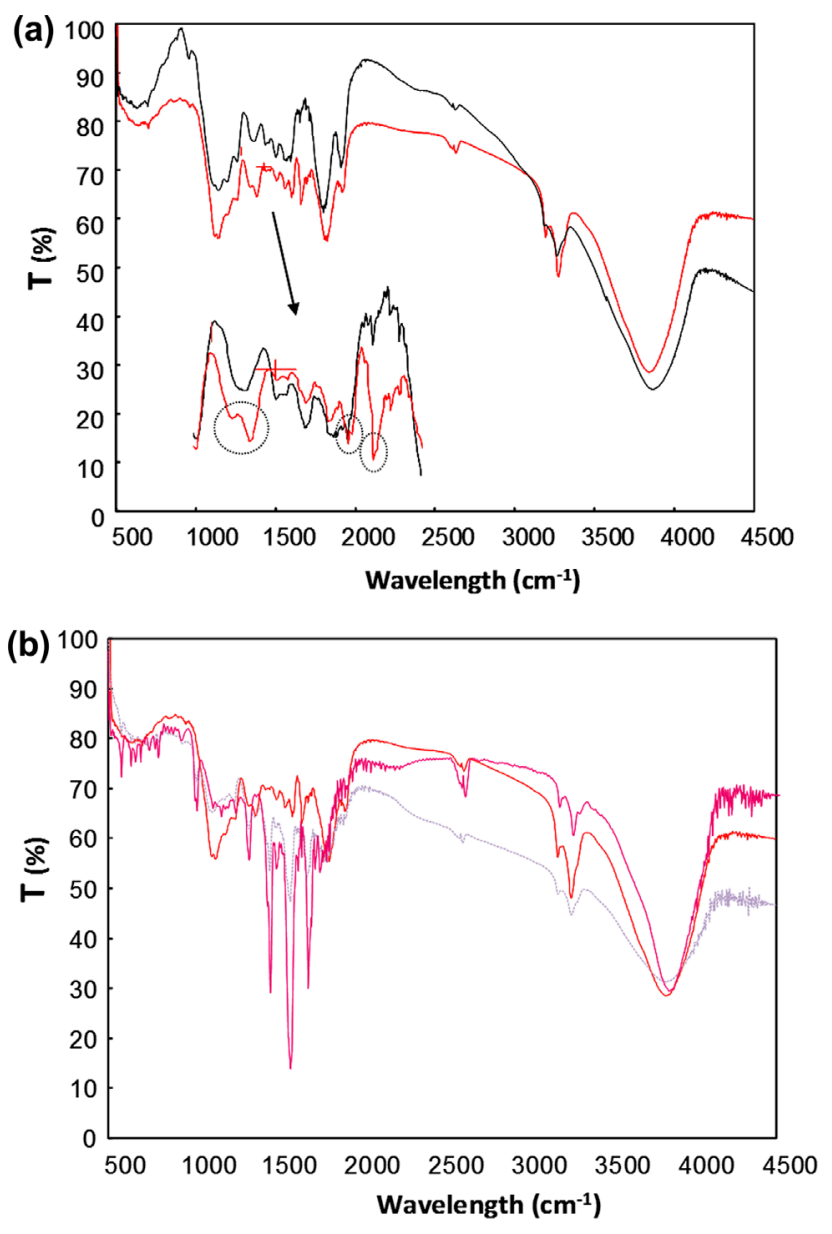

Fig. 3. FTIR spectra: (A) of the adsorbent PSH (1) and of Erythrosine B adsorbed-PSH (2) and (B) of adsorbed-PSH (3); of the mixture of Ery-BH (4) and of the dye Ery (5). the high concentration of $\mathrm{H}^{+}$, so the electrostatic attraction between the adsorbent and the adsorbate (which is an anionic dye) is enhanced. At lower $\mathrm{pH}$, the number of positively charged adsorbent surface sites increased at the expense of the number of negatively charged surface sites.

The carboxyl group of Ery B is protonated and possesses a positive charge density at a lower $\mathrm{pH}$. Lower adsorption of Ery B under alkaline condition is probably due to the presence of $\mathrm{OH}^{-}$ions on the surface of adsorbent competing with the adsorbate (anionic dye) for adsorption sites. Consequently, electrostatic repulsion between the positively charged surface and the charged dye molecule increased with increasing solution $\mathrm{pH}$ and resulted in the decreasing adsorption capacity of Ery B. The surface of the adsorbent was negatively charged at higher $\mathrm{pH}$, which obstructed the adsorption of the negatively charged dye by electrostatic repulsion [36]. A similar trend was observed for the adsorption of Ery B to feathers [1]. The removal of Ery B dye using PSH occurs mainly by ion-exchange reaction. However, the importance of other processes such as electrostatic interactions between highly polar and positively charged vegetable and negatively charged dye molecules and also other intermolecular interactions such as H-bonding between adsorbent and adsorbate (dye) have to be taken into account [37].

\subsubsection{Effect of adsorbent concentration on adsorption efficiency}

In order to investigate the influence of adsorbent concentration on dye adsorption, experiments were
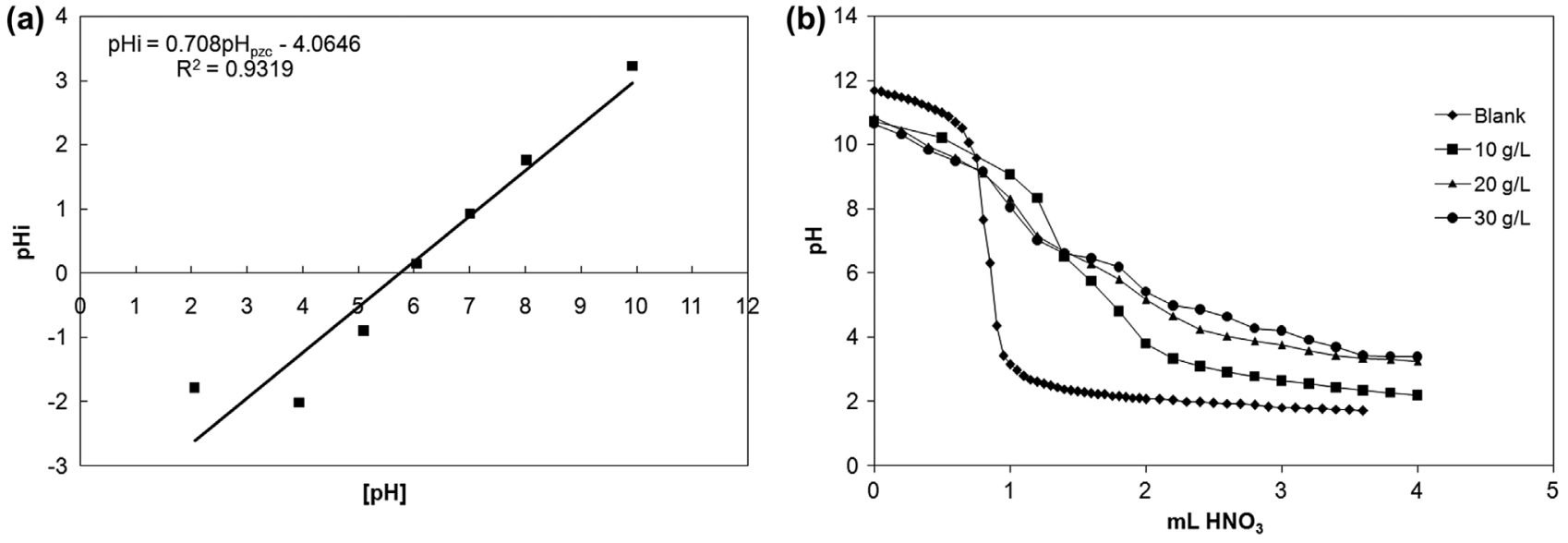

Fig. 4. Point of zero charge of PSH: (a) determined using immersion techniques and (b) determined using potentiometric mass titrations method. 

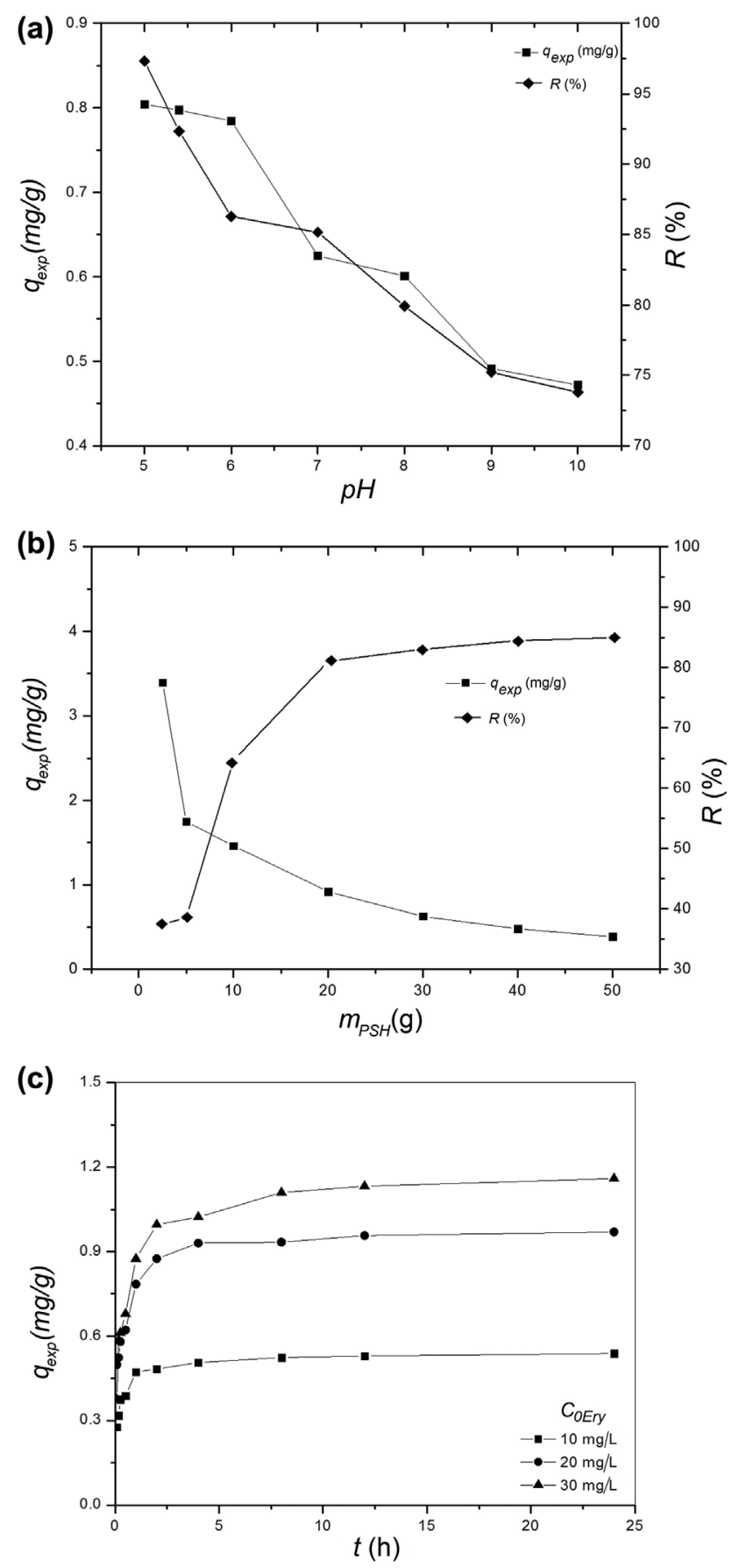

Fig. 5. Effect of some parameters on Erythrosine B uptake $\left(q_{\text {exp }}, \mathrm{mg} / \mathrm{g}\right):$ (a) $\mathrm{pH}\left(C_{0 \mathrm{Ery}}=20 \mathrm{mg} / \mathrm{L} ; C_{\text {OPSH }}=20 \mathrm{~g} / \mathrm{L}\right)$; adsorbent dose $\left(C_{\mathrm{OPSH}}=20 \mathrm{mg} / \mathrm{L} ; \mathrm{pH} 5.6\right)$; (c) contact time (for different initial concentration of Erythrosine B).

carried out at initial dye concentration of $20 \mathrm{mg} / \mathrm{L}$, while the concentration in solution adsorbed varied from 5 to $50 \mathrm{~g} / \mathrm{L}$. Fig. 5(b) shows the results of Ery B adsorption, at equilibrium, for various adsorbent dosages. The intersection point between the adsorption capacity $(q, \mathrm{mg} / \mathrm{g})$ and the removal efficiency $(R \%)$ is at about $8.0 \mathrm{~g}$ PSH, being considered the optimum dose [38]. In our case, the amount of Ery B removed at this value is low, corresponding to a removal efficiency around $55 \%$. When the dosage of PSH is higher than $20 \mathrm{~g} / \mathrm{L}$, the percentage of dye removed achieves $85 \%$ and the concentration become almost constant, the curve approaching a plateau. The adsorbent dose of $20 \mathrm{~g} / \mathrm{L}$ was established as optimal for further studies, since it corresponds to a suitable amount of dye removal $(3.75 \mathrm{mg} / \mathrm{g})$. The increase in the adsorption efficiency with the adsorbent dosage can be attributed to a larger total surface area and the availability of more adsorption sites [17,39]. At adsorbent dosage higher than $0.5 \mathrm{~g}$, the concentration of the dye on the adsorbent surface is in equilibrium with the dye concentration in solution [37]. This result can be explained by the change in the concentration gradient between the dye content in solution and the surface of the adsorbent $[39,40]$.

\subsubsection{Effect of contact time and initial dye concentration on uptake capacity of the adsorbent}

The effect of contact time on the adsorption of Ery $\mathrm{B}$ on PSH was studied at the room temperature, varying the initial dye concentration from 10 to $30 \mathrm{mg} / \mathrm{L}$. The effect of contact time on Erythrosine B uptake using 50 and $100 \mathrm{mg} / \mathrm{L}$ was investigated at various temperature $\left(20,3040\right.$, and $\left.50^{\circ} \mathrm{C}\right)$. The results indicate that the amount of dye adsorbed per mass unit of PSH increased with contact time for the three dye concentrations tested, and achieved the apparent equilibrium after $3 \mathrm{~h}$. The initial Ery $\mathrm{B}$ concentration influences the dye uptake as well, which increases from 0.55 to $1.18 \mathrm{mg} / \mathrm{g}$, being higher for the assay with $30 \mathrm{mg} / \mathrm{L}$ initial dye concentration (Fig. 5(c)).

Figs. 6(a) and (b) show the results obtained with two dye concentrations: 50 and $100 \mathrm{mg} / \mathrm{L}$ Ery B, respectively, at different temperatures. In the case of the solution with an initial concentration of $50 \mathrm{mg} / \mathrm{L}$ Ery $\mathrm{B}$, the dye uptake is around $1.5 \mathrm{mg} / \mathrm{g}$ at $20^{\circ} \mathrm{C}$, and around $2.2 \mathrm{mg} / \mathrm{g}$ at $50^{\circ} \mathrm{C}$. For the solution of the dye containing of $100 \mathrm{mg} / \mathrm{L}$ Ery B, the dye uptake is around $2.25 \mathrm{mg} / \mathrm{g}$ at $20^{\circ} \mathrm{C}$, and around $2.5 \mathrm{mg} / \mathrm{g}$ at $50^{\circ} \mathrm{C}$.

\subsection{Factorial analysis of main and interaction effects of factors affecting the Ery B uptake}

To illustrate better the influence of process parameters on the sorption process, the experimental data were also studied and interpreted using factorial analysis, 

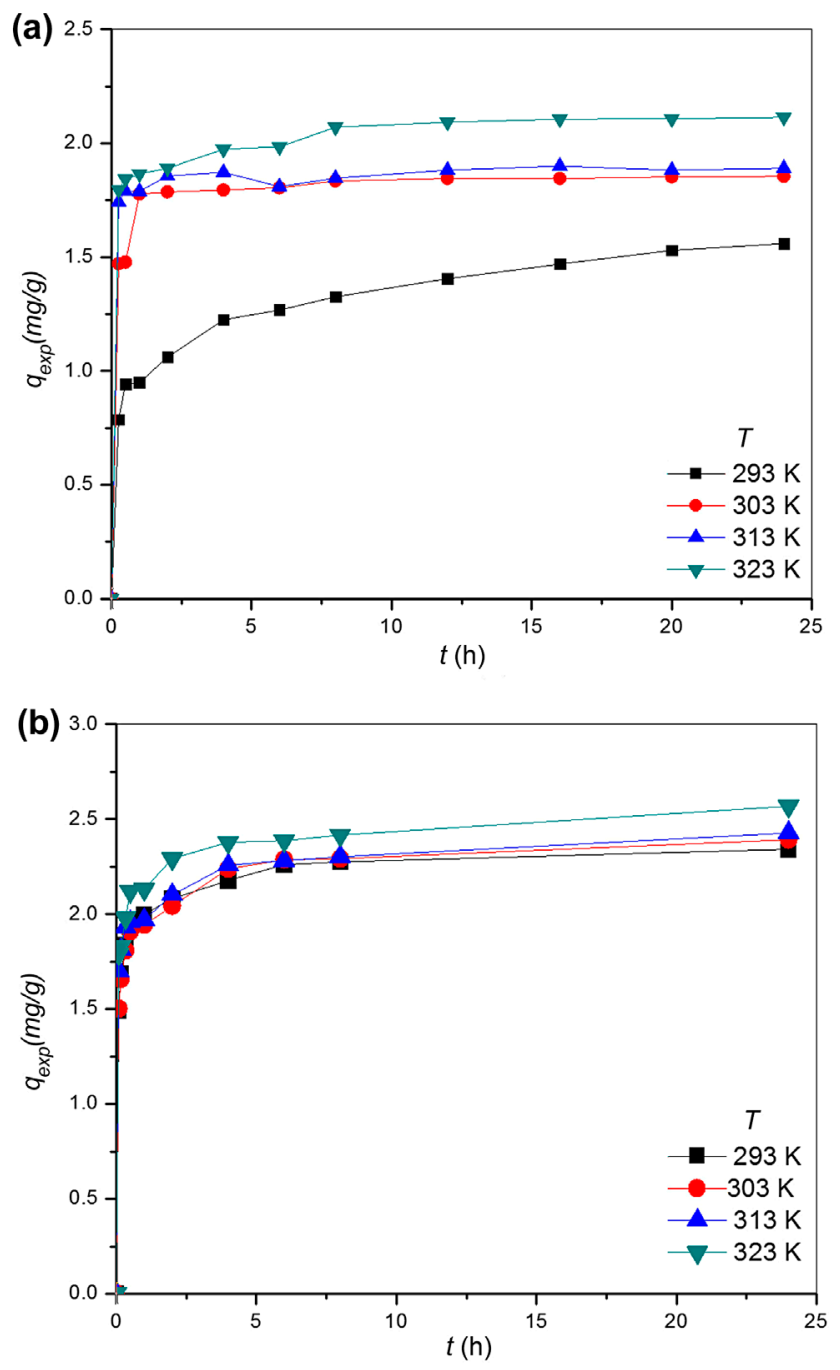

Fig. 6. Effect of contact time for (a) $C_{0 \text { Ery }}=50 \mathrm{mg} / \mathrm{L}$ and (b) $C_{0 \text { Ery }}=100 \mathrm{mg} / \mathrm{L}$ Erythrosine $\mathrm{B}$ at different temperature.

which allowed the analysis of variance and the fitting of response surfaces. We considered the Ery B uptake as the dependent variable in the sorption process, since it can be used as a scale-up and design parameter.

The factorial design matrix and Ery B uptake $\left(q_{\exp }\right.$ $(\mathrm{mg} / \mathrm{g}))$ measured in each factorial experiment is shown in Table 2, with the low $(-1)$ and high $(+1)$ levels as specified in Table 1. ANOVA and $p$-value significant levels were used to check the significance of the effect of independent variables from Table 2, on the dependent variable-Ery B uptake. The ANOVA Tables ( 3 and 4) includes the sum of squares of residuals and regressions together with the corresponding degrees of freedom, $F$-values $T$-values, $p$-values, and ANOVA coefficients (i.e. coefficients of multiple determination $R^{2}$ and adjusted $\left.R(\operatorname{adj})^{2}\right)$.
The mathematical expressions used for calculation of the ANOVA estimators (i.e. SS, MS, $F$-value, $R^{2}$, and $\left.R(\text { adj. })^{2}\right)$ are extensively accessible in the literature $[31,41]$.

The adequacy of the model has been assessed by residuals $(\varepsilon \%)$ considering the differences between experimental $\left(Y_{\exp }\right)$ and predicted $\left(Y_{\text {pred }}\right)$ values (Eq. (5)) [41]:

$\varepsilon \%=\frac{Y_{\exp }-Y_{\text {pred }}}{Y_{\exp }} \times 100$

In Fig. 7, the observed residuals were plotted vs. the predicted values, which show that the model proposed is adequate. The results reported in Fig. 7 show the goodness-of-fit between the predicted values of Ery B uptake, $q_{\text {pred }}$ model, and the corresponding set of experimentally observed values, $q_{\text {exp }}$.

The Box-Cox transformation $Y^{\lambda}$ was applied to obtain a normal distribution of data, with $\lambda=2$, in the form $Y^{2}$ [42]. Accordingly, the Ery B uptake by PSH can be expressed by Eq. (6), in terms of actual variables:

$$
\begin{aligned}
q_{\mathrm{pred}}^{2}= & 1.876-0.0564 \mathrm{pH}-0.05179 C_{0 \mathrm{PSH}}+0.000886 t \\
& +0.03436 T+0.00826 C_{0 \text { Ery }}
\end{aligned}
$$

subjected to minimum and maximum values of intervals for each variable presented in Table 1.

Main and interaction effects, coefficients of the model, standard deviation of each coefficient, and probability for the $2^{5-1}$ factorial designs are shown in Table 4 . The obtained $R^{2}$ indicates good fitting to the experimental results, meaning that the model can explain $96.34 \%$ of the variability in the response. Adjusted $R^{2}(R \text { (adj. })^{2}$ ) can also indicate the good fitting, while it corrects the $R^{2}$ value for the sample size and the number of terms in the model using the degrees of freedom on its computation. Currently, the adjusted $R^{2}$ value $(94.51 \%)$ is closer to the predicted $R^{2}$ value, fitting well the statistical model (Table 4). These statistical estimators prove that the model (6) is statistically suitable for the prediction of the response over the valid region of experimentation considered in the study. The effect of each factor was statistically significant at $p<0.05$ [42].

The main effects of process variables $\mathrm{pH}, \mathrm{C}_{\mathrm{OPSH}}, t$, $T, C_{0 \text { Ery }}$ upon Ery B uptake and interactions effect of the process parameters were examined by means of graphical response surface analysis using contour and surface plots, which are shown in Figs. 8-10, being 
Table 2

Design matrix and results of the $2^{5-1}$ fractional factorial design

\begin{tabular}{|c|c|c|c|c|c|c|c|c|c|c|c|c|c|}
\hline \multirow[b]{2}{*}{ Experiment } & \multicolumn{6}{|c|}{ Coded variables } & \multicolumn{5}{|c|}{ Natural variables } & \multirow[b]{2}{*}{$\begin{array}{l}{ }^{\mathrm{a}} q_{\text {pred }} \\
(\mathrm{mg} / \mathrm{g})\end{array}$} & \multirow[b]{2}{*}{$\begin{array}{l}{ }^{\mathrm{a}} q_{\exp } \\
(\mathrm{mg} / \mathrm{g})\end{array}$} \\
\hline & $x_{0}$ & $x_{1}$ & $x_{2}$ & $x_{3}$ & $x_{4}$ & $x_{5}$ & $\begin{array}{l}x_{1} \\
(\mathrm{pH})\end{array}$ & $\begin{array}{l}x_{2} \mathrm{C}_{\mathrm{OPSH}} \\
(\mathrm{mg} / \mathrm{L})\end{array}$ & $\begin{array}{l}x_{3} t \\
(\min )\end{array}$ & $\begin{array}{l}x_{4} T \\
\left({ }^{\circ} \mathrm{C}\right)\end{array}$ & $\begin{array}{l}x_{5} C_{0 \text { Ery }} \\
(\mathrm{mg} / \mathrm{L})\end{array}$ & & \\
\hline 1 & +1 & -1 & -1 & -1 & -1 & -1 & 5 & 2.5 & 5 & 20 & 5 & 1.4824 & 1.3872 \\
\hline 2 & +1 & +1 & -1 & -1 & -1 & +1 & 10 & 2.5 & 5 & 20 & 100 & 1.6432 & 1.5409 \\
\hline 3 & +1 & -1 & +1 & -1 & -1 & +1 & 5 & 50 & 5 & 20 & 100 & 0.7226 & 0.8749 \\
\hline 4 & +1 & +1 & +1 & -1 & -1 & -1 & 10 & 50 & 5 & 20 & 5 & 0.7379 & 0.5486 \\
\hline 5 & +1 & -1 & -1 & +1 & -1 & +1 & 5 & 2.5 & 2,880 & 20 & 100 & 2.3514 & 2.4062 \\
\hline 6 & +1 & +1 & -1 & +1 & -1 & -1 & 10 & 2.5 & 2,880 & 20 & 5 & 2.1125 & 2.0800 \\
\hline 7 & +1 & -1 & +1 & +1 & -1 & -1 & 5 & 50 & 2,880 & 20 & 5 & 1.5115 & 1.4139 \\
\hline 8 & +1 & +1 & +1 & +1 & -1 & +1 & 10 & 50 & 2,880 & 20 & 100 & 1.6695 & 1.5677 \\
\hline 9 & +1 & -1 & -1 & -1 & +1 & +1 & 5 & 2.5 & 5 & 50 & 100 & 2.0032 & 1.9424 \\
\hline 10 & +1 & +1 & -1 & -1 & +1 & -1 & 10 & 2.5 & 5 & 50 & 5 & 1.7164 & 1.6161 \\
\hline 11 & +1 & -1 & +1 & -1 & +1 & -1 & 5 & 50 & 5 & 50 & 5 & 0.8764 & 0.9501 \\
\hline 12 & +1 & +1 & +1 & -1 & +1 & +1 & 10 & 50 & 5 & 50 & 100 & 1.1273 & 1.1038 \\
\hline 13 & +1 & -1 & -1 & +1 & +1 & -1 & 5 & 2.5 & 2,880 & 50 & 5 & 2.4032 & 2.4814 \\
\hline 14 & +1 & +1 & -1 & +1 & +1 & +1 & 10 & 2.5 & 2,880 & 50 & 100 & 2.5056 & 2.6352 \\
\hline 15 & +1 & -1 & +1 & +1 & +1 & +1 & 5 & 50 & 2,880 & 50 & 100 & 2.0248 & 1.9692 \\
\hline 16 & +1 & +1 & +1 & +1 & +1 & -1 & 10 & 50 & 2,880 & 50 & 5 & 1.7416 & 1.6429 \\
\hline
\end{tabular}

a only four digits were kept after the decimal point in the Table, while the statistical analysis was performed with all decimal resulted from the calculus.

Table 3

Analysis of Variance for Transformed Response

\begin{tabular}{llccll}
\hline Source & DF & Adj SS & Adj MS & $F$-value & $p$-value \\
\hline Regression & 5 & 57.2044 & 11.4409 & 52.65 & 0.000 \\
$\mathrm{pH}$ & 1 & 0.3183 & 0.3183 & 1.46 & 0.254 \\
$C_{0 \mathrm{PSH}}$ & 1 & 24.2082 & 24.2082 & 111.41 & 0.000 \\
$t$ & 1 & 25.9637 & 25.9637 & 119.48 & 0.000 \\
$T$ & 1 & 4.2500 & 4.2500 & 19.56 & 0.001 \\
$C_{0 \text { Ery }}$ & 1 & 2.4642 & 2.4642 & 11.34 & 0.007 \\
Error & 10 & 2.1730 & 0.2173 & & \\
Total & 15 & 59.3774 & & & \\
\hline
\end{tabular}

Notes: DF-Degrees of Freedom; SS-sum of squared errors; MS-Mean Square error.

supportive in predicting that each level of the factors affects the response (i.e. $q_{\text {pred }}$ ) in different ways.

The sign of the main effect indicates the directions of the effect. It can be seen from Fig. 12, that the effects of $C_{0 \mathrm{PSH}}, t, T, C_{0 \mathrm{Ery}}$ on Ery B uptake are positive, with different slopes of variation, when their values increases. On contrary, the increase in $\mathrm{pH}$ can produce a diminishing in mean values of Ery B uptake. The variation profiles confirm the results described in the Section 3.2 and the model (Eq. (6)). Contour plots (Fig. 9), which are the projection of the response surfaces (Fig. 10) as a two-dimensional plane give a better
Table 4

Coefficients for Transformed Response

\begin{tabular}{llllll}
\hline & \multicolumn{5}{c}{$\mathrm{SE}$} \\
Term & Coefficient & Coefficient & T-value & $p$-value & VIF \\
\hline Constant & 1.876 & 0.507 & 3.70 & 0.004 & \\
$\mathrm{pH}$ & -0.0564 & 0.0466 & -1.21 & 0.254 & 1.00 \\
$C_{\text {OPSH }}$ & -0.05179 & 0.00491 & -10.55 & 0.000 & 1.00 \\
$t$ & 0.000886 & 0.000081 & 10.93 & 0.000 & 1.00 \\
$T$ & 0.03436 & 0.00777 & 4.42 & 0.001 & 1.00 \\
$C_{\text {OEry }}$ & 0.00826 & 0.00245 & 3.37 & 0.007 & 1.00
\end{tabular}

Model Summary for Transformed Response

\begin{tabular}{lllr}
\hline$S$ & $R^{2}$ & $R(\mathrm{adj})^{2}$ & $R$ (pred) $^{2}$ \\
0.4661 & $96.34 \%$ & $94.51 \%$ & $90.63 \%$ \\
\hline
\end{tabular}

understanding of the influence of variables and their interaction on the response, as discussed in the Section 3.2. Both Figs. 9 and 10 reveal that a maximum value of Ery B sorption was not evidenced in the intervals of variables selected in this study. Therefore, apart of the main and interaction effects among variables demonstrated here, further studies will be performed to solve the optimization problem consisting in searching (by simulation) the input combination of design variables that maximizes the investigated response (Ery B uptake and removal efficiency). 

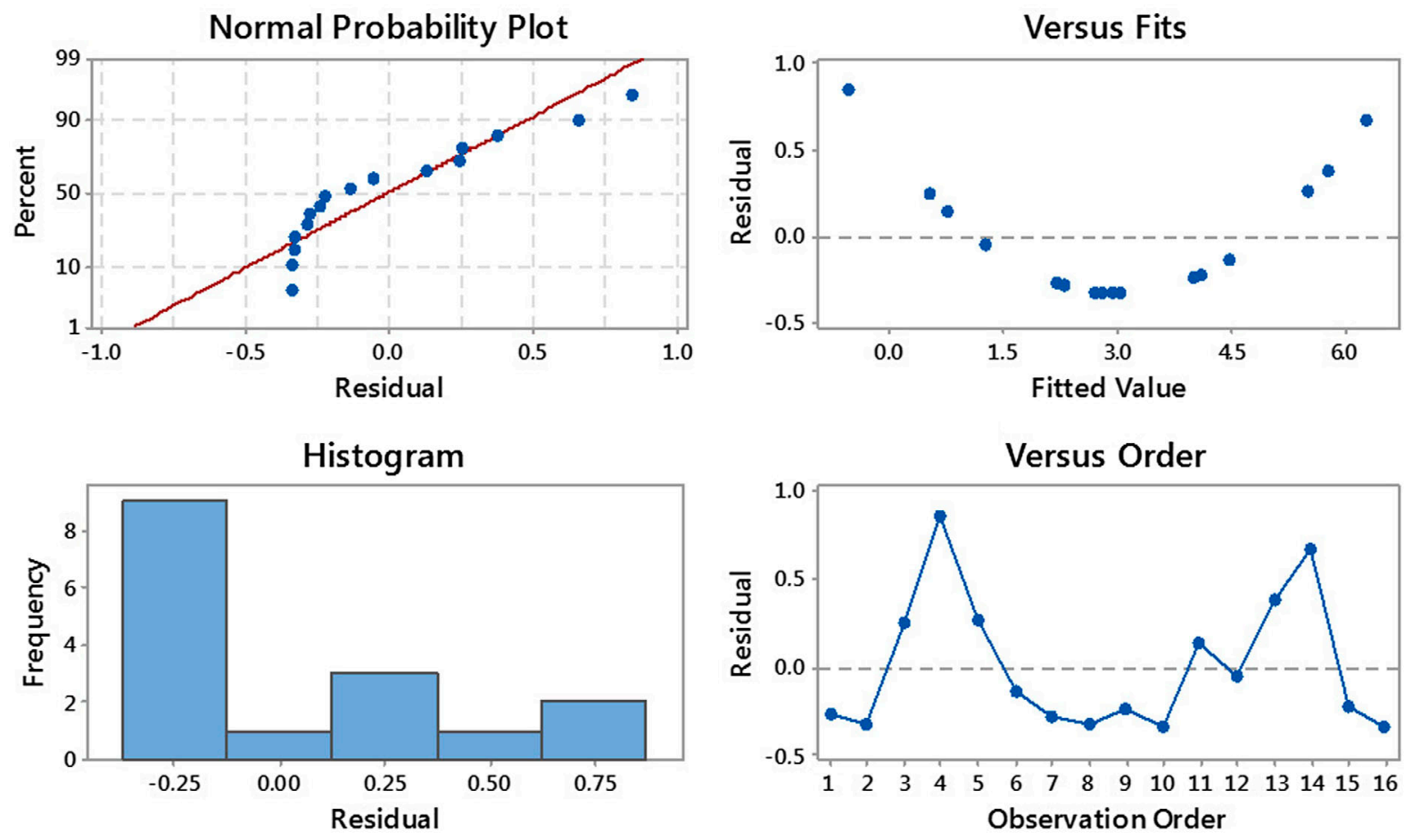

Fig. 7. Residuals related to predicted response for Erythrosine B uptake.

\subsection{Adsorption equilibrium}

In fact, the equilibrium relationship between the Ery B concentrations in solution and adsorbent is described by the adsorption isotherms, which help the understanding of the process mechanism. Studies on the adsorption equilibrium of Ery B on PSH agrowaste as adsorbent were carried out using solutions of 20-400 mg/L dye. Fig. 11(a) shows the adsorption isotherms obtained for the PSH-Ery B system.

For all temperatures studied, the shape of experimental data suggests an L-type isotherm, reflecting a high affinity between dye and adsorbent, and also a rapid adsorption. The influence of temperature on the process is significant at $50^{\circ} \mathrm{C}$, the adsorption being faster and the equilibrium was not reached for the dye concentrations used in experiments.

The data resulted from the adsorption experiments are usually represented by equilibrium isotherms. In the present study the results were analyzed based four isotherm models: Langmuir, Freundlich, Temkin, and Dubinin-Radushkevich.

The fundamental assumption of the Langmuir isotherm model is that adsorption takes place at specific sites on the adsorbent surface [41-43]. The data obtained based on the Langmuir isotherm model are presented in Table 5, and indicated that the adsorption of Ery B was favorable at all the studied temperatures (Fig. 11(b)).

The Freundlich isotherm is an empirical equation based on the hypothesis that the adsorption takes place on a heterogeneous surface and also possibly in multilayer adsorption. The isotherm is applied especially for organic compounds or highly interactive species [44-46]. The Freundlich constants $K_{\mathrm{F}}$ and $n$ are the indicative of the extent of the adsorption process; $n$ is a measure of adsorption intensity (Table 5). The slope ranges between 0 and 1 and is a measure of surface heterogeneity: the closer the slope is to zero, the more heterogeneous is the surface (Fig. 11(c)). A value below unity implies chemisorptions process where $1 / n$ above one is an indicative of cooperative adsorption.

Temkin isotherm encloses a factor that explicitly takes into the account adsorptive-adsorbent interactions. This isotherm assumes that the heat of adsorption of all the molecules on the adsorbent surface layer decreases linearly with coverage due to adsorbent-adsorbate interactions, and that the adsorption is characterized by a uniform distribution of binding energies, up to some maximum values [47] (Fig. 11(d); Table 5).

Liquid-phase adsorption data were also analyzed using the Dubinin-Radushkevich isotherm model 

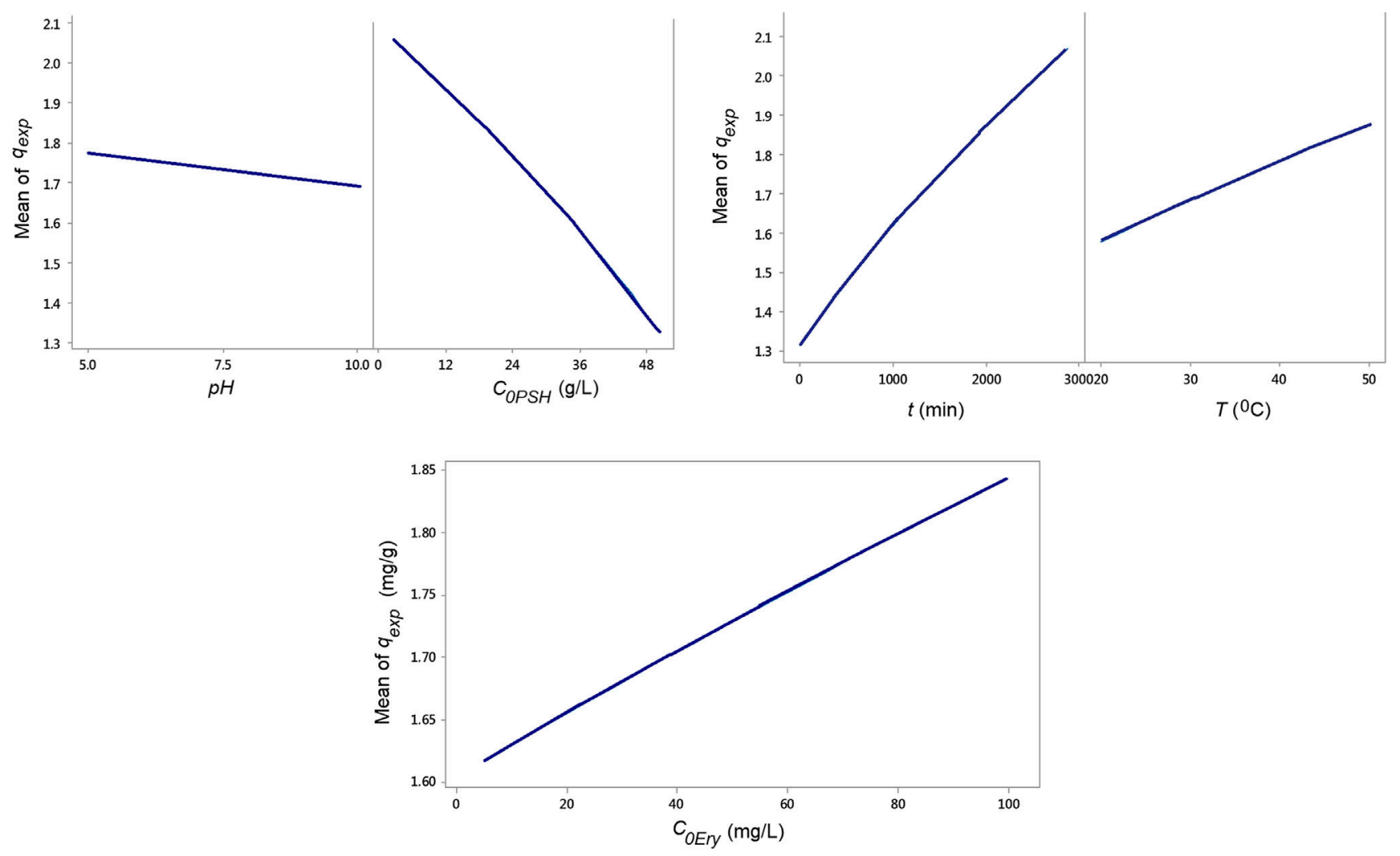

Fig. 8. Main effect plots for Erythrosine B uptake by PSH.

applied usually for the estimation of the apparent free energy of adsorption [48]. In deriving this equation for liquid-phase adsorption, the amount adsorbed corresponding to any adsorbate concentration is assumed to be a Gaussian function of the Polanyi potential, $\varepsilon$, [43]. A linear plot of $\ln q_{\mathrm{e}}$ against $\varepsilon^{2}$ would give the values of $q_{\mathrm{DR}}$ and $B$ (thus the mean free energy of adsorption, E) from the intercept and slope (Fig. 11(e)). The values of $q_{\mathrm{DR}}, B$, and $E$ for the adsorption of Erythrosine $B$ were determined and the results are shown in Table 5.

The isotherms constants and regression coefficients for the Ery B adsorption are presented in Table 5. Ery $\mathrm{B}$ adsorption process was well described by all isotherm models with $R^{2}$ values ranging between 0.99 and 0.91 . The determined values of dye uptake increase with temperature increasing. This confirms an endothermic adsorption process as was found by Ho and McKay [49] and Patil et al. [50] in their studies. The value of Langmuir separation factor, $R_{\mathrm{L}}$, less than unity indicates highly favorable adsorption of the studied adsorbent. The adsorption capacity of the adsorbent PSH for Ery B uptake was between 5 and $20.5 \mathrm{mg} / \mathrm{g}$. These values are close to the data obtained by Hameed and El-Khaiary [51] for the adsorption of the cationic dye Methylen Blue on a particular type of $\mathrm{PSH}$ at around $30^{\circ} \mathrm{C}$, namely $10.13 \mathrm{mg} / \mathrm{g}$. The difference may be explained by the structure of the dyes and ionic charge.

The values obtained for the molecular parameter $b_{\mathrm{T}}$ are negative for temperatures of 20,30 , and $40^{\circ} \mathrm{C}$, and positive for $50^{\circ} \mathrm{C}$ and showed that repulsion exists in the adsorption layer at the lower temperature tested, as was found by Arami et al. [52] and Nandi et al. [53], as well. The value of $K_{\mathrm{T}}$ increases with temperature increasing, which suggests that the dye is absorbed on the adsorbent surface through weak interactions [52,53]. For the natural unmodified materials such as PSH used in this study, it is highly probable that the adsorption sites are energetically non-equivalent [54].

From the Dubinin-Radushkevich isotherm, the correlation factors listed showed that the linear fit of $\ln q_{\mathrm{e}}$ against $\varepsilon^{2}$ is fairly good for dye adsorption (Fig. 11(e)). The mean free energy of adsorption $E_{\mathrm{DR}}$ calculated from the Dubinin-Radushkevich equation gives further information about the adsorption mechanism. The values of $E_{\mathrm{DR}}$ were found to be within the range 9$12 \mathrm{~kJ} / \mathrm{mol}$, suggesting that the ion-exchange mechanism is responsible for the adsorption process [55]. 
(a)

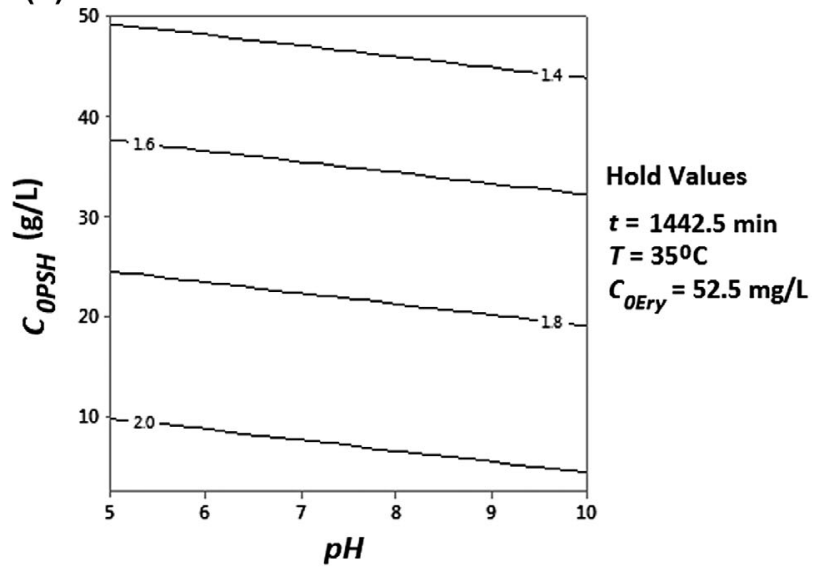

(c)

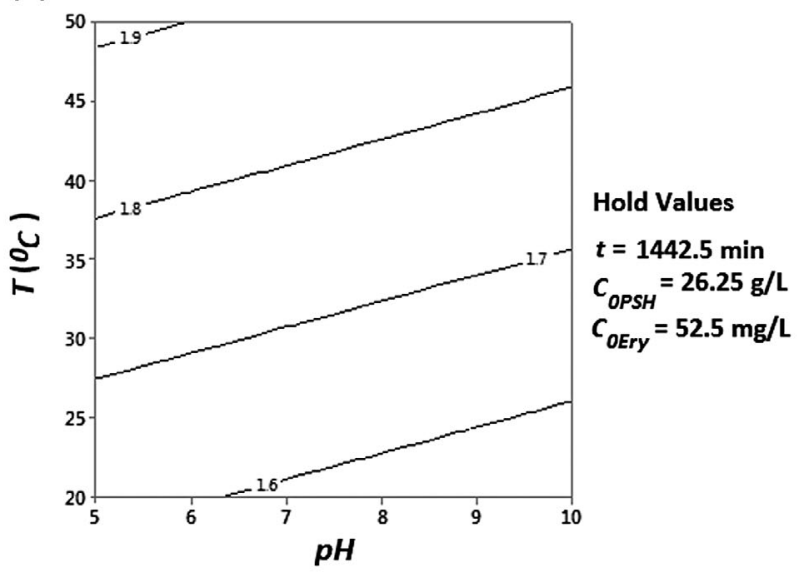

(e)

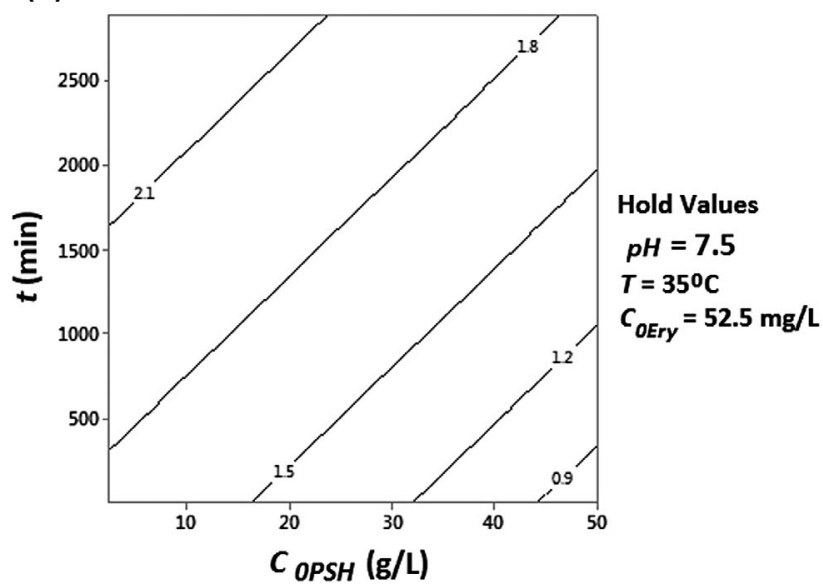

(b)

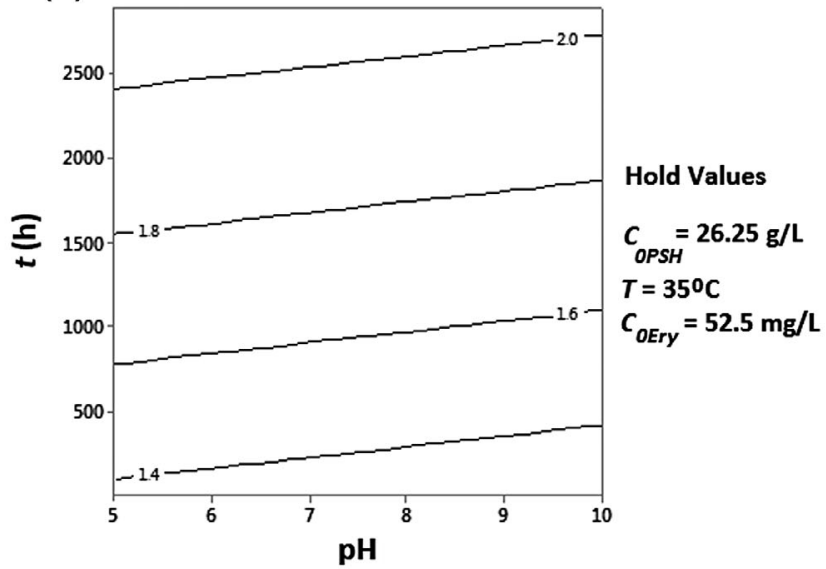

(d)

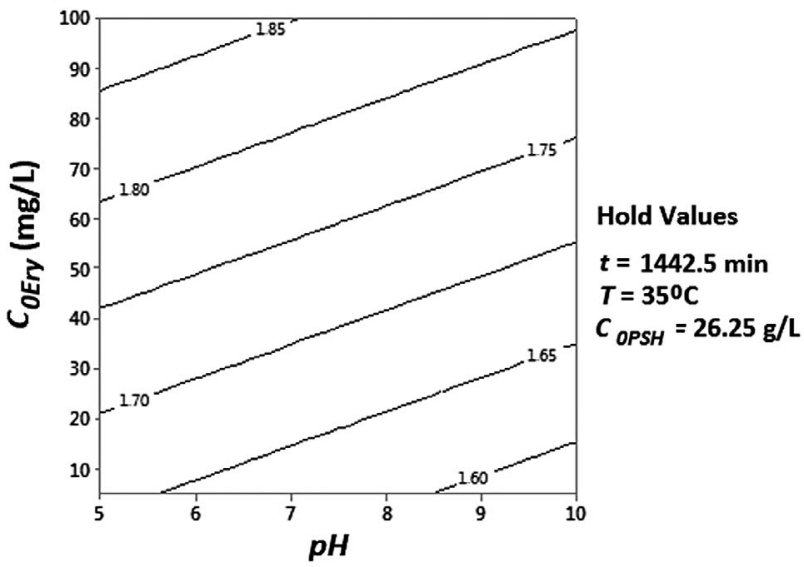

(f)

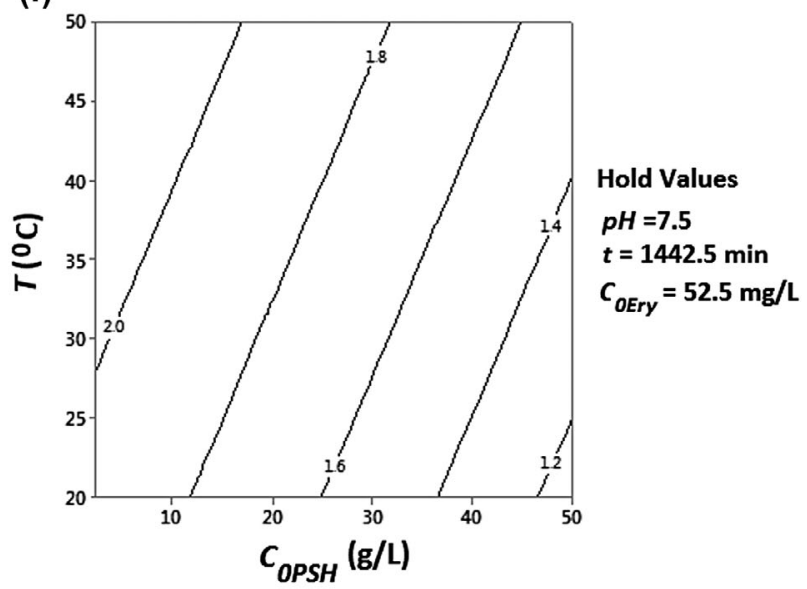

Fig. 9. Contour plots for interaction effects for Erythrosine B uptake by PSH: (a) Contour plot of $q_{\exp }$ vs. $C_{O P S H}, \mathrm{pH}$; (b) Contour plot of $q_{\exp }$ vs. $t, \mathrm{pH}$; (c) Contour plot of $q_{\exp }$ vs. $T, \mathrm{pH}$; (d) Contour plot of $q_{\exp }$ vs. $C_{O E r y}, \mathrm{pH}$; (e) Contour plot of $q_{\exp }$ vs. $C_{\text {OPSH }}, t$; (f) Contour plot of $q_{\exp }$ vs. $C_{\text {OPSH }}, T$; (g) Contour plot of $q_{\exp }$ vs. $C_{\text {OPSH }}, C_{\text {OEry }} ;$ (h) Contour plot of $q_{\exp }$ vs. $T, t$; (i) Contour plot of $q_{\exp }$ vs. $C_{\text {OEry }}, t$; (j) Contour plot of $q_{\exp }$ vs. $C_{O E r y}, T$. 
(g)

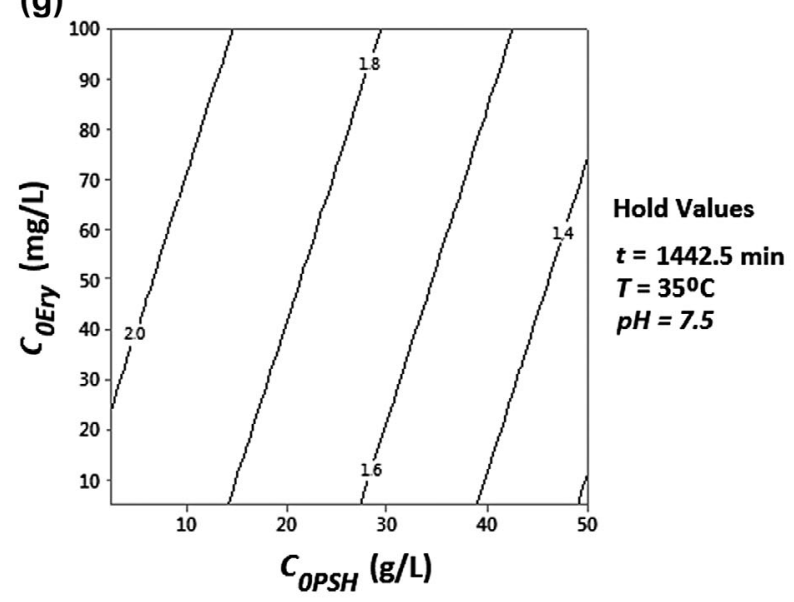

(i)

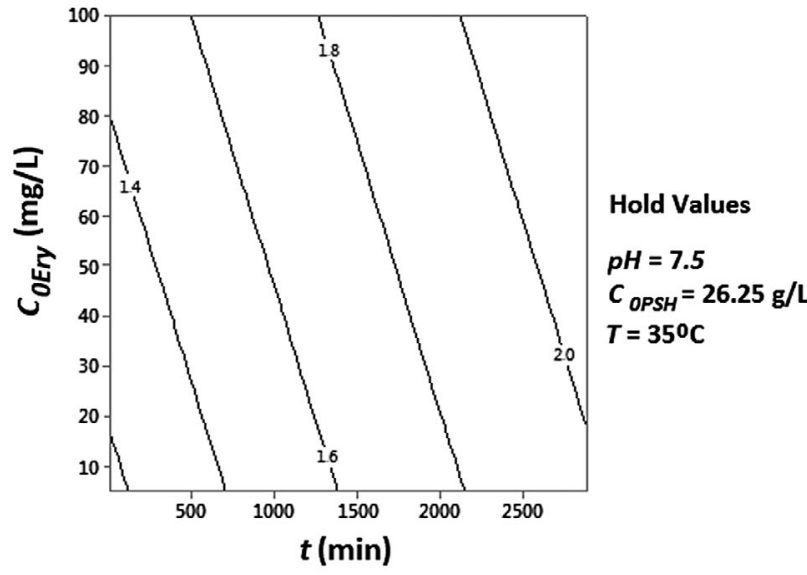

(h)
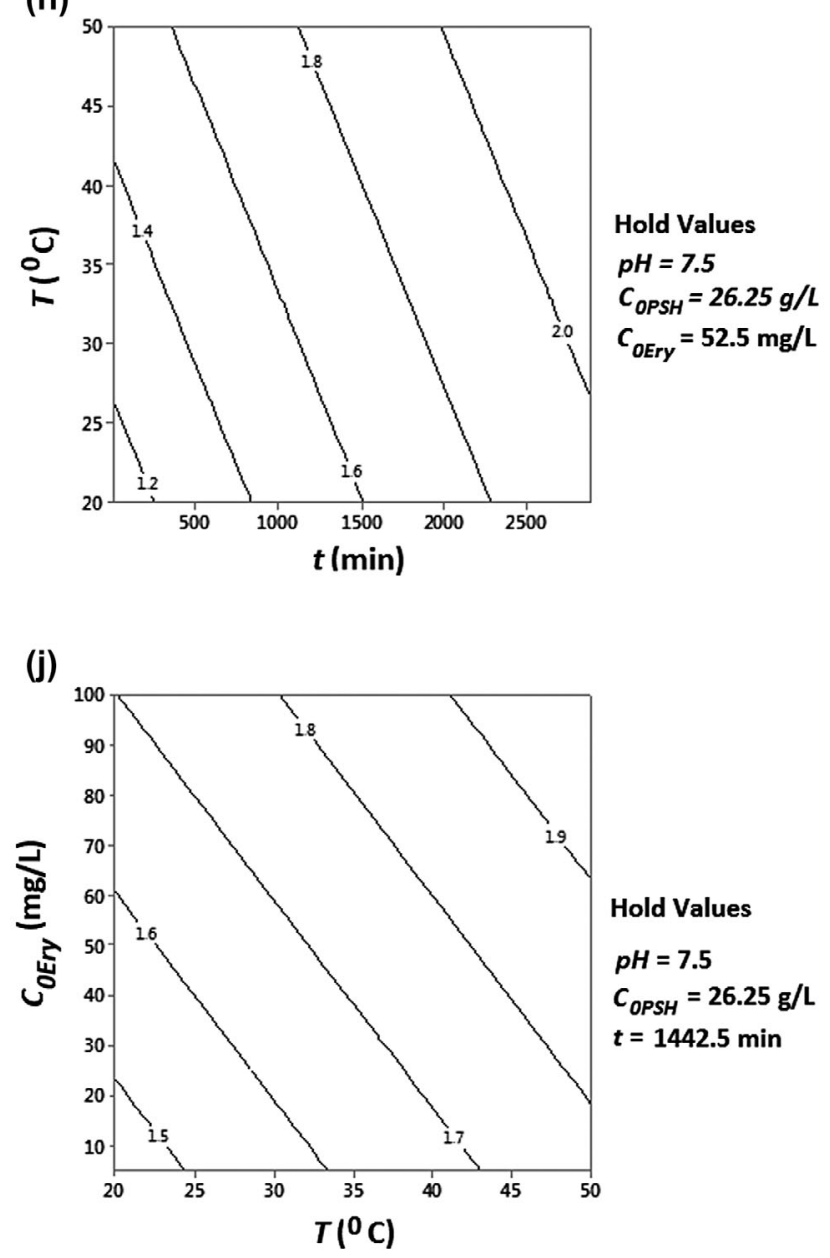

Fig. 9. (Continued).

With the increase of temperature to $50^{\circ} \mathrm{C}$, the value of $E_{\mathrm{DR}}$ increases for PSH from 9.1 to $12 \mathrm{~kJ} / \mathrm{mol}$. The values of Freundlich constant, $n_{\mathrm{F}}$, support this hypothesis (Table 5).

\subsection{Adsorption kinetics}

The adsorption of Ery B on PSH was studied as a function of contact time, so as to determine the required time for equilibrium reaching. The results show that the amount of adsorbed dye increased with any increase in Ery B concentration within the studied interval. The adsorption is initially fast and then becomes progressively slower with increasing of contact time. The process reached equilibrium after $4 \mathrm{~h}$ for Ery B concentration between 10 and $30 \mathrm{mg} / \mathrm{L}$. For higher dye concentration (50 and $100 \mathrm{mg} / \mathrm{L})$ the equilibrium time increased with around one hour. This is probably due to diffusion rate of dye molecules into the macro- and micropores of the adsorbent and to the different functional group on the surface of PSH that can react with the Ery B [56]. Adsorption processes at liquid-solid interface are frequently affected by the diffusional boundary layer, external mass transfer, and intraparticle diffusion.

In order to find out the potential rate-controlling steps involved in the process, four kinetics models were used for data analysis (Lagergren pseudo-firstorder, Ho's pseudo-second-order model, and Elovich model). The Lagergren's pseudo-first-order model and Ho's pseudo-second-order model have been widely used to predict adsorption kinetics (Figs. 12 and 13). The Elovich model applicable for chemisorptions on energetically heterogeneous solid surface is described as the plot of $q$ vs. $\ln t$ (Fig. 14) $[57,58]$. 
a1) Surface plot of $q_{\text {exp }}$ vs. $C_{O P S H}, \mathrm{pH}$

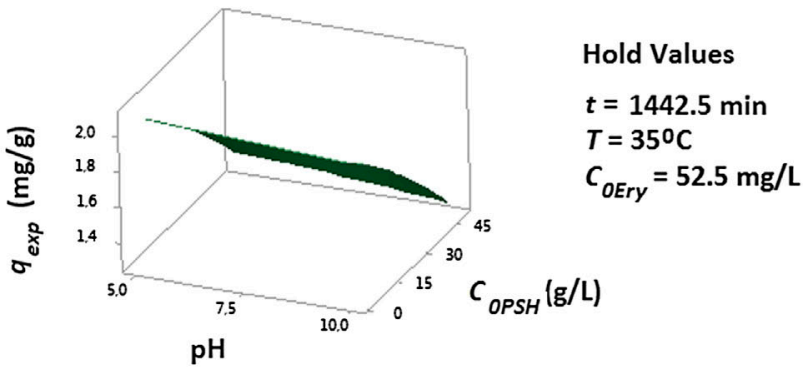

e1) Surface plot of $q_{\exp }$ vs. $C_{O P S H}, t$

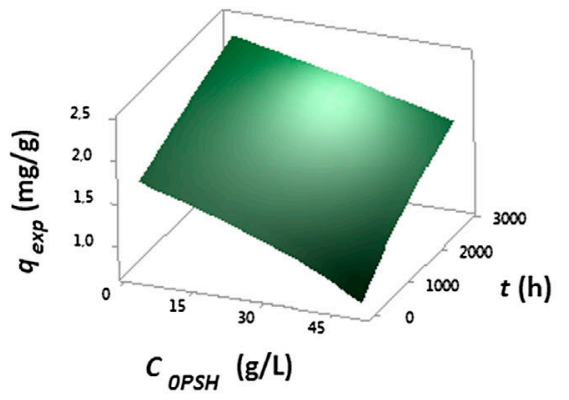

d1) Surface plot of $q_{\text {exp }}$ vs. $C_{\text {OEry }}, \mathrm{pH}$

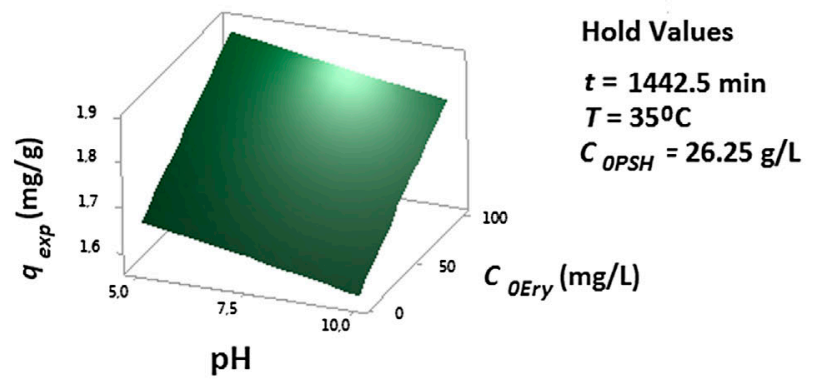

j1) Surface plot of $q_{\text {exp }}$ vs. $C_{\text {OEry }}, T$

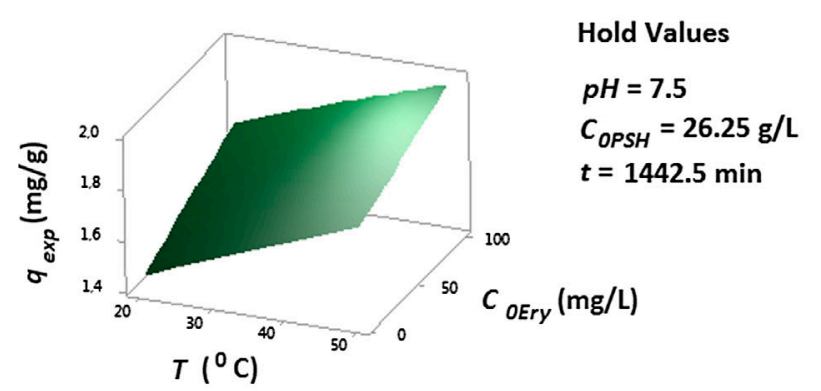

Fig. 10. Surface plots for interaction effects for Erythrosine B uptake by PSH (related to contours a, d, e, j from Fig. 9).

Therefore, the mechanism of adsorption depends on the physical and chemical characteristics of the adsorbent but also on the mass transport process. The overall adsorption process may be controlled by film or external diffusion, pore, and/or surface diffusion and adsorption on the pore surface and a combination of these steps [59]. The possibility of intraparticle diffusion was investigated using the model developed by Weber and Morris [57,60].

The pseudo-first-order equation is generally applicable over the initial stage of the adsorption processes, whereas the pseudo-second-order equation predicts the behavior over the whole range of adsorption. These two models were used in this study to fit the experimental data. It was found that the resulted values of $q_{\mathrm{e}}$ obtained from pseudo-second-order model are much closer to the experimental results than $q_{\mathrm{e}}$ obtained from the Lagergeren's model (Tables 6-7). The highest $R^{2}$ values obtained using the pseudo-second-order equation indicate that the data of adsorption kinetics are well represented by this model. The linear relationships between initial Erythrosine B concentration and the rate constants obtained from pseudo-second-order model suggest that several mechanisms play a role in the adsorption process, such as ion exchange and physical adsorption [49].

Elovich model was also tested to better define for the adsorption process mechanisms of Ery B on PSH (Fig. 14). The kinetic constants resulted from the processing of experimental data according to Elovich equation are presented in Table 6. For the system PSH-Erythrosine B, the values of the coefficient $\alpha$ decreased with any increase in dye concentration, which indicated the formation of large number of bonds between the adsorbent and the acid dye Erythrosine $\mathrm{B}$, whereas the $\beta$ coefficient remains constant.

The first-order and pseudo-second-order kinetic models are not able to identify the diffusion mechanism. Thus, the kinetic results were then analyzed by using the intraparticle diffusion model. Weber and Morris model [61] was applied to investigate the intraparticle diffusion mechanism (Fig. 15). A straight line with slope of the plot $q_{\mathrm{e}}$ vs. $t^{0.5}$ giving $\mathrm{K}_{i}$ and the intercept giving $C$, results when adsorption mechanism follows the intraparticle diffusion process. The deviations of the straight line from the origin suggest that the pore diffusion is not the rate-controlling step. As seen from Fig. 15, the plots were not linear over 
(a)
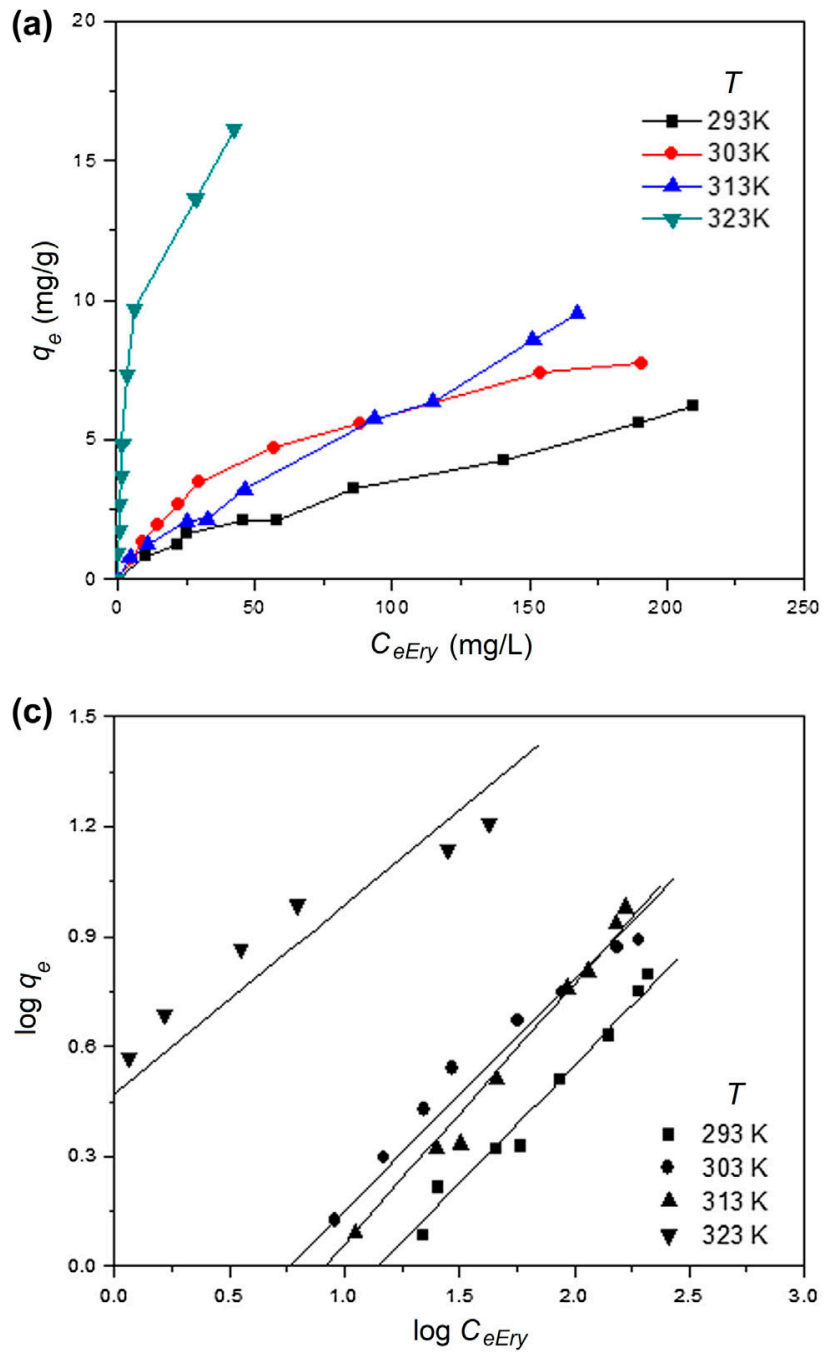

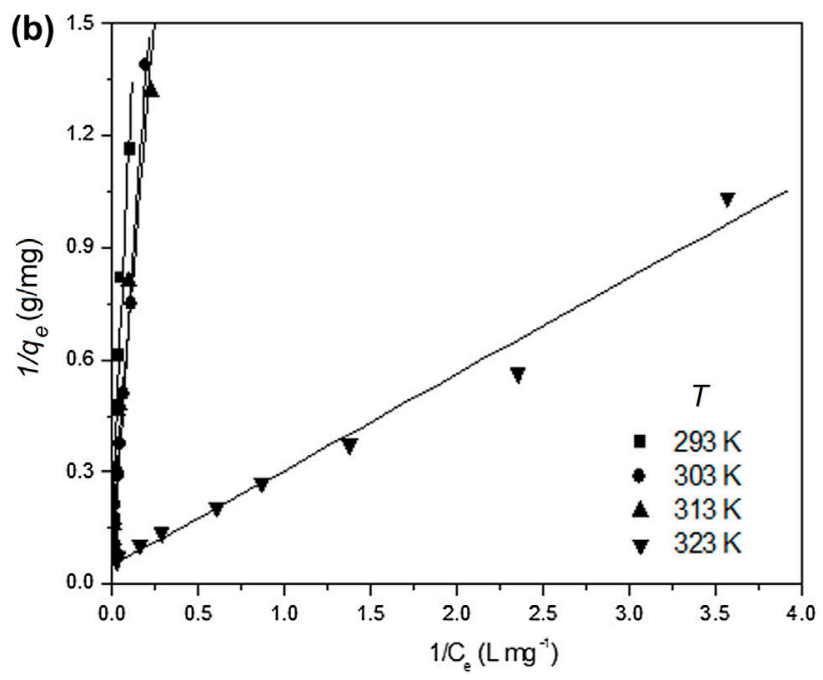

(d)

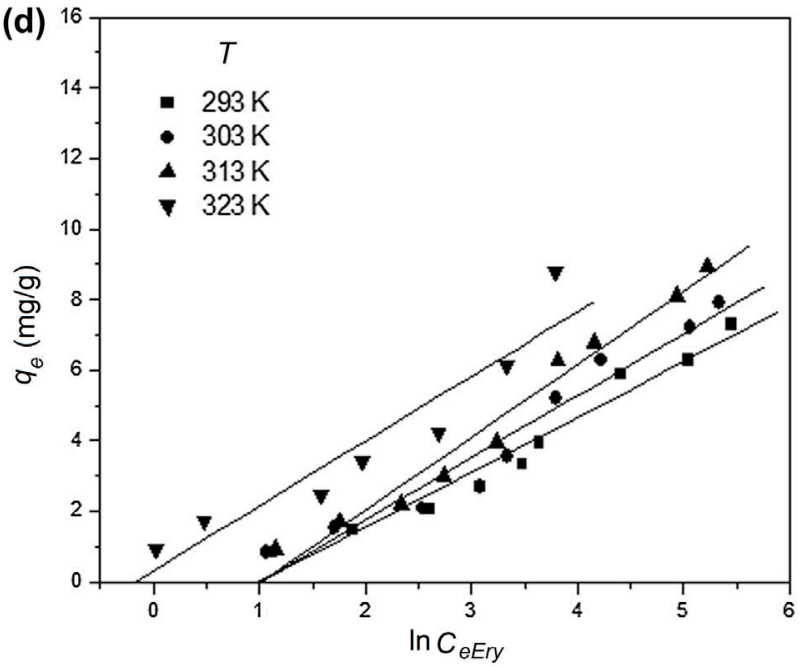

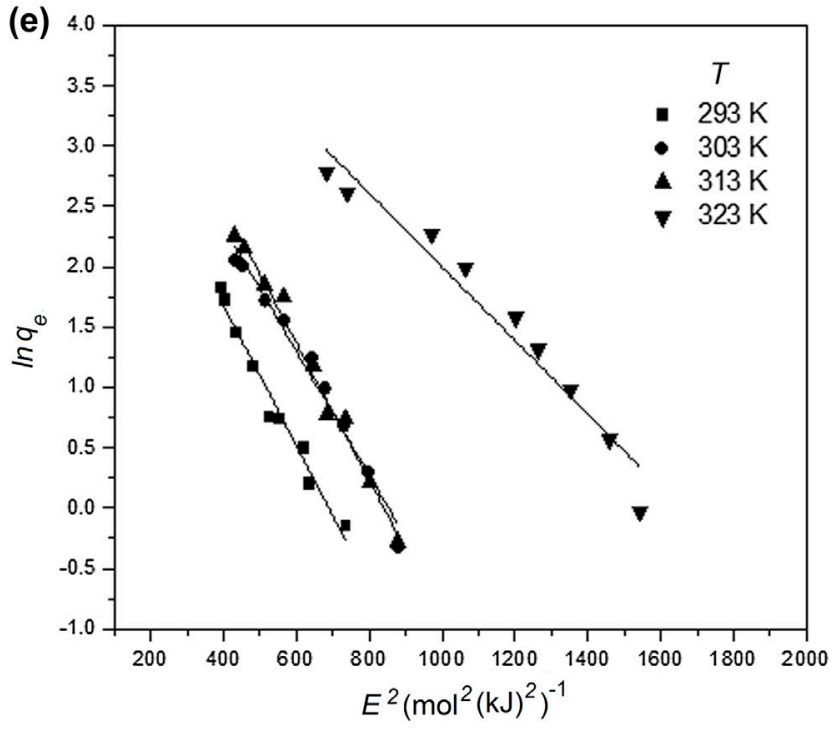

Fig. 11. Adsorption isotherms of Erythrosine B: (a) experimental $\left(C_{0 \mathrm{Ery}}=20-400 \mathrm{mg} / \mathrm{L} ; C_{\mathrm{OPSH}}=20 \mathrm{~g} / \mathrm{L}\right.$ PSH, (b) Langmuir plot, (c) Freundlich plot, (d) Temkin plot, and (e) Dubinin-Radushkevich plot. 
Table 5

Constants of Langmuir, Freundlich, Temkin, and Dubinin-Radushkevich isotherms for the sorption of Erythrosine B onto $\mathrm{PSH}$ at different temperatures

\begin{tabular}{|c|c|c|c|c|c|c|c|c|}
\hline \multirow[b]{2}{*}{$T\left({ }^{\circ} \mathrm{C}\right)$} & \multicolumn{4}{|l|}{ Langmuir } & \multicolumn{4}{|l|}{ Freundlich } \\
\hline & $q_{\max }(\mathrm{mg} / \mathrm{g})$ & $K_{\mathrm{L}}(\mathrm{L} / \mathrm{mg})$ & $R^{2}$ & $R_{\mathrm{L}}$ & $n$ & $K_{\mathrm{F}}(\mathrm{L} / \mathrm{mg})$ & $R^{2}$ & \\
\hline 20 & 5.015 & 0.01224 & 0.968 & 0.11531 & 1.27 & 1.5903 & 0.994 & \\
\hline 30 & 5.9737 & 0.01918 & 0.997 & 0.16961 & 1.72 & 1.5128 & 0.994 & \\
\hline 40 & 12.3152 & 0.03012 & 0.970 & 0.07664 & 1.78 & 1.4602 & 0.987 & \\
\hline \multirow[t]{2}{*}{50} & 20.5634 & 0.1894 & 0.991 & 0.01303 & 1.56 & 1.3162 & 0.982 & \\
\hline & \multicolumn{4}{|c|}{ Temkin isotherm } & \multicolumn{4}{|c|}{ Dubinin-Radushkevich } \\
\hline$T\left({ }^{\circ} \mathrm{C}\right)$ & $b_{\mathrm{T}}(\mathrm{J} / \mathrm{mol})$ & & $K_{\mathrm{T}}(\mathrm{L} / \mathrm{mg})$ & $R^{2}$ & $q_{\mathrm{DR}}(\mathrm{mg} / \mathrm{g})$ & $\beta$ & $E(\mathrm{~kJ} / \mathrm{mol})$ & $R^{2}$ \\
\hline 20 & -0.605 & & 0.0987 & 0.940 & 54.1685 & 0.0058 & 9.285 & 0.970 \\
\hline 30 & -0.782 & & .2042 & 0.990 & 81.1825 & 0.0051 & 9.852 & 0.977 \\
\hline 40 & -0.562 & & .1457 & 0.915 & 120.1691 & 0.0057 & 9.380 & 0.985 \\
\hline 50 & 0.68 & & 3.6882 & 0.993 & 156.1005 & 0.0031 & 12.804 & 0.946 \\
\hline
\end{tabular}

the whole time range, implying that more than one process affected the adsorption and the acid dyes adsorption by different size of pores can be observed. A similar behavior was reported for the methylene blue adsorption onto palm kernel fibers [62]. The two linear sections with different slopes for concentrations higher than $10 \mathrm{mg} / \mathrm{L}$ ) were assigned to two interparticle diffusion steps occurring during the adsorption process. The slopes of the linear sections of the plots are shown in Table 8 . The first portion was attributed to the diffusion of acid dyes through the solution to the external surface of adsorbent, or the boundary layer diffusion of solute molecules. The second portion described the gradual adsorption stage, where intraparticle diffusion, the equilibrium stage, was rate limiting. The intraparticle diffusion started to slow down due to the extremely low dye concentration left in the solution or the rate of uptake might be limited by the size of adsorbate molecule, concentration of the adsorbate and its affinity to the adsorbent, diffusion coefficient of the acid dye in the bulk phase, the pore size distribution of the adsorbent [63]. This is confirmed for PSH since $K_{\mathrm{i} 2}<K_{\mathrm{i} 1}$, and also it can be said that the global adsorption process was controlled by intraparticle diffusion in pores.

According to the $R^{2}$ values for the four kinetic models (between 0.99 and 0.89) applied the reaction can be described by pseudo-second-order model, suggesting that the adsorption mechanism involves ion exchange and physical interactions. The Ery B adsorption mechanism was predominantly intraparticle diffusion but there was also a dependence on pore size as the dye diffuses through different pore sizes (macropores, mesopores, and micropores).

\subsection{Adsorption thermodynamic parameters}

Thermodynamic parameters, namely Gibb's free energy change $\left(\Delta G^{\circ}\right)$, enthalpy $\left(\Delta H^{\circ}\right)$, and entropy $\left(\Delta S^{\circ}\right)$ changes were assessed from the Langmuir constants and van't Hoff plots, respectively using Eqs. (7) and (8), where: $\Delta G^{\circ}=$ change in free energy, $\mathrm{kJ} / \mathrm{mol}$; $\Delta H^{\circ}=$ change in enthalpy, $\mathrm{kJ} / \mathrm{mol} ; \Delta S^{\circ}=$ change in entropy, $\mathrm{J} / \mathrm{mol} \mathrm{K} ; T=$ absolute temperature, $K ; R=$ universal gas constant $=8.314 \times 10^{-3} ; K_{\mathrm{L}}=$ distribution coefficient, L/mol.

$$
\begin{aligned}
& \Delta G^{\circ}=-R \times T \times \ln K_{\mathrm{L}} \\
& \Delta G^{\circ}=\Delta H^{\circ}-T \times \Delta S^{\circ}
\end{aligned}
$$

Thermodynamic parameters calculated from the slope and intercept of Van't Hoff plots [64] (Fig. 16) are shown in Table 9. The negative values of $\Delta G^{\circ}$ demonstrate that Ery B adsorption is spontaneous for the range of temperature evaluated. The positive values of enthalpy change $\left(\Delta H^{\circ}\right)$ shows that the adsorption process is endothermic, while any increasing in temperature lead to a higher Ery B amount uptake at equilibrium.

The positive values of $\Delta S^{\circ}$ obtained for the Ery BPSH system reveals the affinity of the dye towards the adsorbent and an increased disorder, while some structural changes in the Ery B can occur during adsorption.

\subsection{Desorption of the dye}

Desorption studies help to elucidate the nature of adsorption, the possibility to recycle the adsorbent 

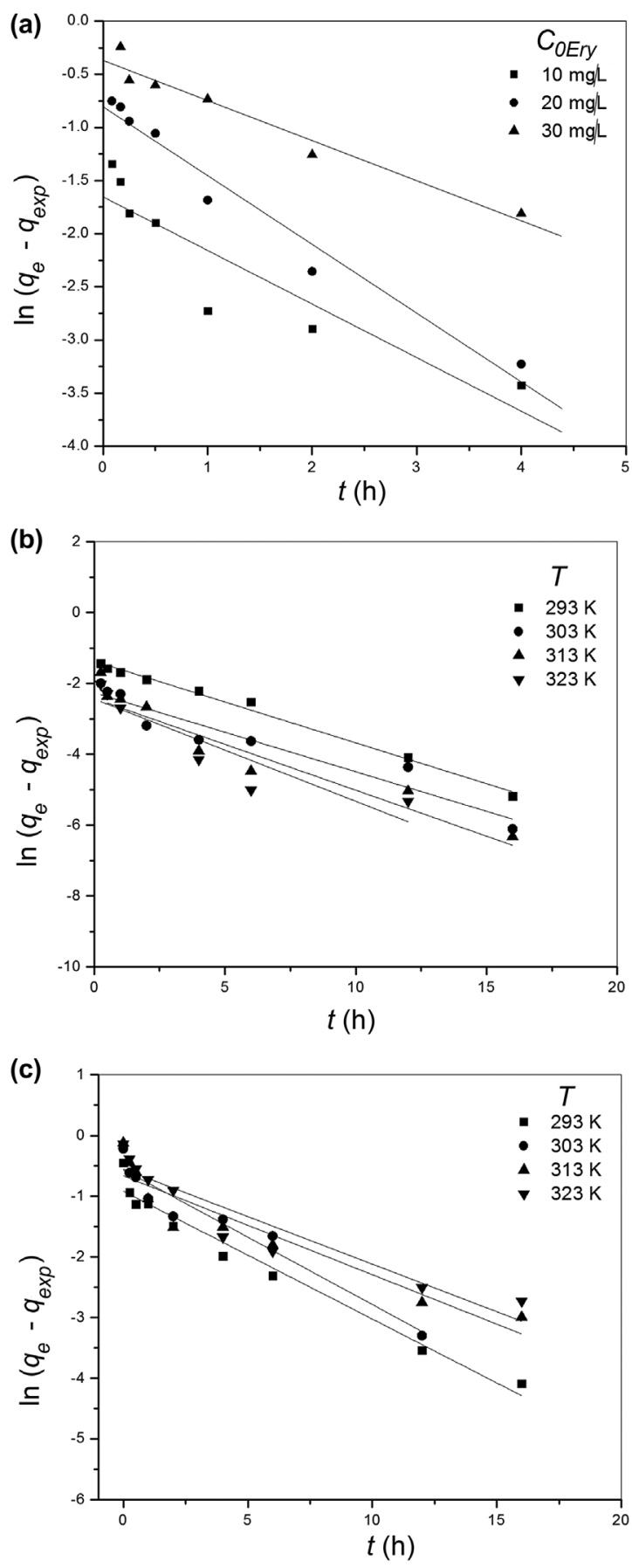

Fig. 12. Lagergren model applied for Erythrosine B adsorption on PSH: (a) different initial concentrations of Erythrosine $\mathrm{B}$ at $T=25^{\circ} \mathrm{C}, \mathrm{pH} 5.6$, and $\mathrm{C}_{\mathrm{OPSH}}=20 \mathrm{~g} / \mathrm{L}$; and different temperatures: (b) $C_{0 \text { Ery }}=50 \mathrm{mg} / \mathrm{L}$ Erythrosine $\mathrm{B}$ and (c) $C_{0 \text { Ery }}=100 \mathrm{mg} / \mathrm{L}$ Erythrosine B.

and the dye recovery. If the adsorbed dyes can be desorbed using neutral $\mathrm{pH}$ water, the attachment of the dyes on the adsorbent is weak. If sulfuric acid or alka-
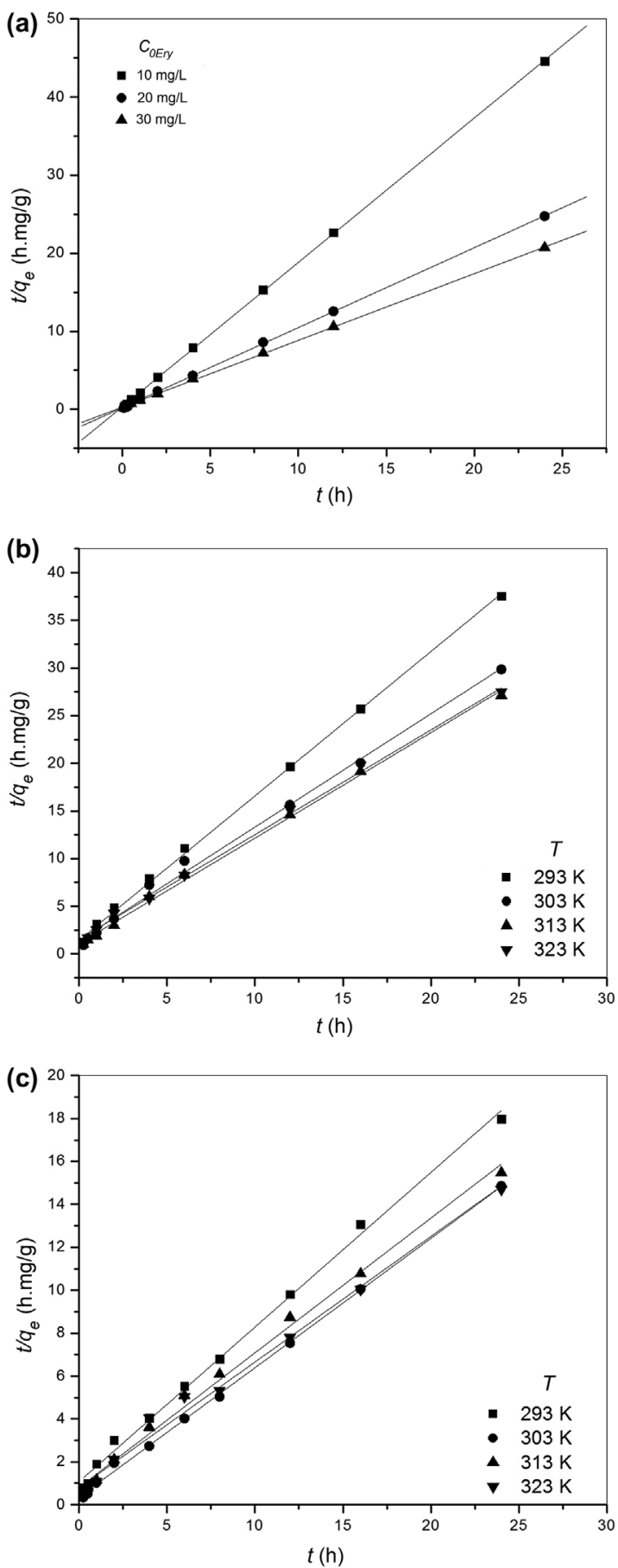

Fig. 13. Ho's pseudo-second-order model applied for Erythrosine B adsorption on PSH: (a) different initial concentrations of Erythrosine $\mathrm{B}$ at $T=25^{\circ} \mathrm{C}, \mathrm{pH} 5.6$, and $\mathrm{C}_{\mathrm{OPSH}}=$ $20 \mathrm{~g} / \mathrm{L}$ adsorbent; and different temperatures: (b) $C_{0 \text { Ery }}=$ $50 \mathrm{mg} / \mathrm{L}$ Erythrosine $B$ and (c) $C_{0 \text { Ery }}=100 \mathrm{mg} / \mathrm{L}$ Erythrosine B.

line water can facilitate the dye desorption, then adsorption would be facilitated by ion-exchange mechanisms. If organic acids, like acetic acid can desorb the 


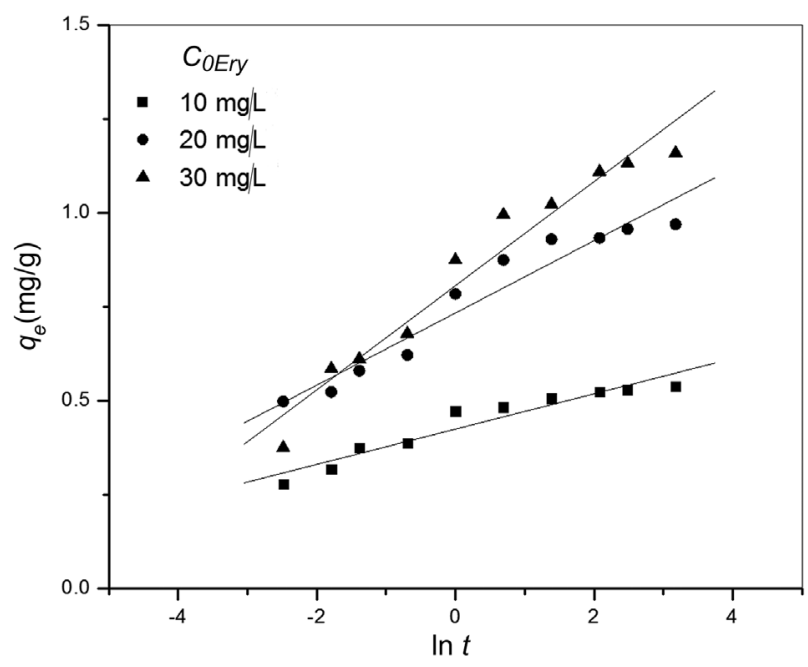

Fig. 14. Elovich model applied adsorption of different initial Erythrosine B concentrations on PSH $\left(T=25^{\circ} \mathrm{C}, \mathrm{pH}\right.$ 5.6, $\left.C_{\mathrm{OPSH}}=20 \mathrm{~g} / \mathrm{L}\right)$. dyes, then the dye is attached to the adsorbent through chemisorption [65].

The adsorbent saturated with pollutant can be used as fuel or in producing asphalt concrete. Fig. 17(a) illustrated the desorption percentage of the dye using different solution at $50^{\circ} \mathrm{C}$. The results show a low amount of dye desorbed for all the solution used, amount which reflect a strong interaction between the agro waste surface and the dyes molecules, excepting the $\mathrm{NaOH}(\mathrm{pH} 10)$, where the percentage desorbed is around 17\%. These results show that the adsorption is by ion exchange, and these results in accordance with Dubinin-Raduschevich free energy of adsorption $E_{\mathrm{DR}}$, calculated from isotherm equation.

Four solutions were chosen to test the efficiency of the adsorption-desorption process in three cycle of Ery B soption on PSH (I cycle (IS; ID), II cycle (IIS; IID), III cycle (IIIS; IIID)). Isopropanol proved to be the most efficient solvent for Ery B desorption from

Table 6

Pseudo-first-order, Pseudo-second-order, and Elovich constants for different initial dye concentrations at $T=25^{\circ} \mathrm{C}, \mathrm{pH}$ 5.6 , and $C_{0 P S H}=20 \mathrm{~g} / \mathrm{L}$ concentration of sorbent

\begin{tabular}{|c|c|c|c|c|c|c|c|c|c|c|}
\hline \multirow[b]{2}{*}{$\mathrm{C}_{0 \text { Ery }}(\mathrm{mg} / \mathrm{L})$} & \multicolumn{3}{|c|}{$\begin{array}{l}\text { Pseudo-first-order } \\
\text { parameters }\end{array}$} & \multicolumn{4}{|c|}{ Pseudo-second-order parameters } & \multicolumn{3}{|c|}{ Elovich parameters } \\
\hline & $q_{\mathrm{e}}(\mathrm{mg} / \mathrm{g})$ & $k_{1}(1 / \mathrm{h})$ & $R^{2}$ & $q_{\exp }(\mathrm{mg} / \mathrm{g})$ & $q_{\mathrm{e}}(\mathrm{mg} / \mathrm{g})$ & $k_{2}(\mathrm{~g} / \mathrm{mg} \mathrm{h})$ & $R^{2}$ & $\alpha(\mathrm{mg} / \mathrm{g} \mathrm{h})$ & $\beta(\mathrm{g} / \mathrm{mg})$ & $R^{2}$ \\
\hline 10 & 0.192 & 0.504 & 0.967 & 0.538 & 0.540 & 10.551 & 0.999 & 40.185 & 21.308 & 0.921 \\
\hline 20 & 0.446 & 0.6470 & 0.983 & 1.097 & 0.975 & 4.903 & 0.999 & 19.956 & 10.405 & 0.936 \\
\hline 30 & 0.691 & 0.377 & 0.978 & 1.83 & 1.169 & 2.657 & 0.999 & 4.682 & 7.219 & 0.953 \\
\hline
\end{tabular}

Table 7

Pseudo-first-order and Pseudo-second-order rate constants for 50 and $100 \mathrm{mg} / \mathrm{L}$ Erythrosine B sorption on PSH at different temperature, $\mathrm{pH} 5.6$, and $20 \mathrm{~g} / \mathrm{L}$ sorbent concentration

\begin{tabular}{|c|c|c|c|c|c|c|c|}
\hline \multirow[b]{2}{*}{$T\left({ }^{\circ} \mathrm{C}\right)$} & \multicolumn{3}{|c|}{ Pseudo-first-order parameters } & \multicolumn{4}{|c|}{ Pseudo-second-order parameters } \\
\hline & $q_{\mathrm{e}}(\mathrm{mg} / \mathrm{g})$ & $k_{1}(1 / \mathrm{h})$ & $R^{2}$ & $q_{\exp }(\mathrm{mg} / \mathrm{g})$ & $q_{\mathrm{e}}(\mathrm{mg} / \mathrm{g})$ & $k_{2}(\mathrm{~g} / \mathrm{mg} \mathrm{h})$ & $R^{2}$ \\
\hline & \multicolumn{7}{|c|}{$50 \mathrm{mg} / \mathrm{L}$ Erythrosine B } \\
\hline 20 & 0.2538 & 0.2306 & 0.9911 & 1.264 & 0.7063 & 2.96 & 0.998 \\
\hline 30 & 0.1041 & 0.2232 & 0.9111 & 1.731 & 0.8974 & 9.55 & 0.999 \\
\hline 40 & 0.8840 & 0.2588 & 0.9298 & 1.792 & 0.9219 & 11.58 & 0.999 \\
\hline \multirow[t]{2}{*}{50} & 0.8723 & 0.2888 & 0.8976 & 2.105 & 0.9583 & 17.39 & 0.999 \\
\hline & \multicolumn{7}{|c|}{100 mg/L Erythrosine B } \\
\hline 20 & 0.8934 & 0.1618 & 0.8813 & 1.927 & 1.5167 & 1.372 & 0.998 \\
\hline 30 & 1.1338 & 0.4352 & 0.9420 & 2.152 & 1.8595 & 5.7133 & 0.999 \\
\hline 40 & 1.0168 & 0.1678 & 0.9469 & 2.202 & 1.9 & 4.2184 & 0.999 \\
\hline 50 & 1.1373 & 0.2112 & 0.9420 & 2.468 & 1.9939 & 4.1289 & 0.999 \\
\hline
\end{tabular}




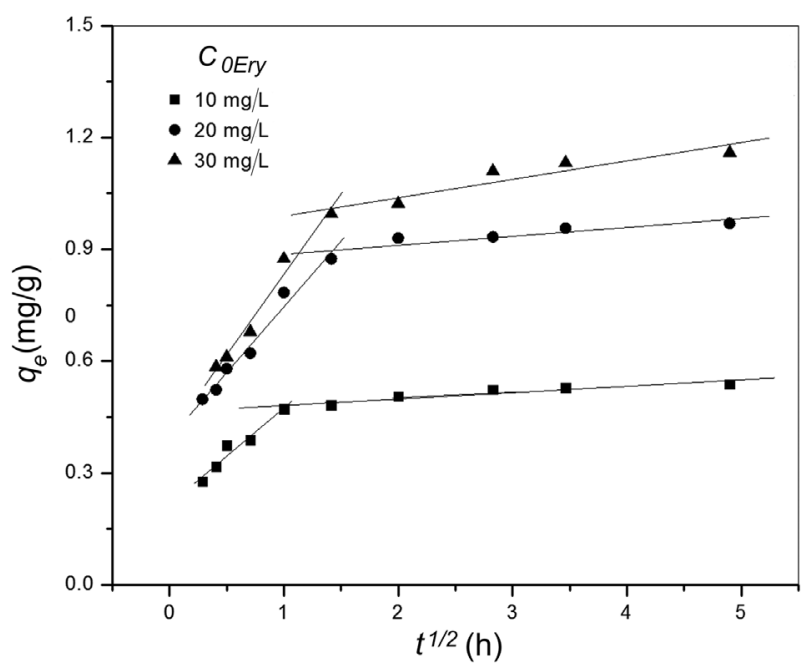

Fig. 15. Intraparticle diffusion model applied adsorption of different initial Erythrosine B concentrations on PSH $\left(T=25^{\circ} \mathrm{C}, \mathrm{pH} 5.6, \mathrm{C}_{\mathrm{OPSH}}=20 \mathrm{~g} / \mathrm{L}\right)$.

Table 8

Constants in intraparticle diffusion model

\begin{tabular}{lllll}
\hline & & \multicolumn{2}{c}{ Intraparticle diffusion parameters } \\
\cline { 3 - 5 }$C_{\text {OPSH }}(\mathrm{g} / \mathrm{L})$ & & $K_{\mathrm{i}}\left(\mathrm{mg} / \mathrm{g} \mathrm{min}^{1 / 2}\right)$ & $C_{\mathrm{i}}$ & $R^{2}$ \\
\hline 10 & I & 0.2587 & 0.2159 & 0.97 \\
& II & 0.0149 & 0.4725 & 0.939 \\
20 & I & 0.3525 & 0.3934 & 0.988 \\
& II & 0.0240 & 0.863 & 0.891 \\
30 & I & 0.4312 & 0.4019 & 0.988 \\
& II & 0.0493 & 0.9399 & 0.940 \\
\hline
\end{tabular}

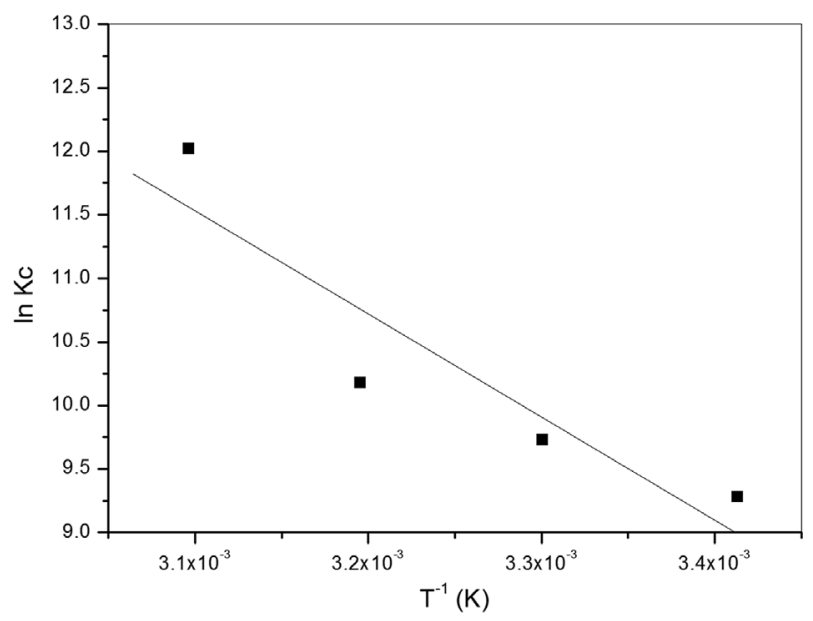

Fig. 16. Plot of $\ln K_{\mathrm{L}}$ vs. $T^{-1}$ for the removal of Erythrosine $\mathrm{B}$ by PSH. the PSH adsorbent (Fig. 17(b)). In the case of acetone, the adsorption process efficiency is higher for the three cycles than any other solution used (Fig. 17(b)). The efficiency of ethanol and isopropanol in Ery B desorption from PSH may be attributed to the dye property.

Even if Ery B desorption showed that the dye can be recovered using ethanol and isopropanol, the method is not economic and unfriendly in terms of environmental protection because the best solvents used for this process are VOC that pollute the atmosphere and have a high price. An alternative to close the life cycle of expended adsorbent, PSH containing Ery $\mathrm{B}$, is their embedding in the anaerobic digestion process with other vegetable waste or incineration with energy recovery.

\subsection{Adsorption mechanism}

The structure complexity of the agrowaste induces an elaborated adsorption process of Erythrosine B on PSH. The kinetic study of the adsorption process showed that, at the beginning there is a linear region representing the rapid surface loading, and in the end a horizontal linear region represents the equilibrium.

The adsorption process generally is sustained through ionic, chemical, and physical interactions. SEM and FTIR studies can provide important information regarding the possible mechanism in dye adsorption. SEM of PSH before and after dye adsorption indicated that the dye molecules adsorb on the adsorbent surface (Fig. 2). The FTIR study indicated the presence of different functional groups on the adsorbent surface such as: $-\mathrm{OH}\left(3,420-3,450 \mathrm{~cm}^{-1}\right)$ attributed to phenolic acids contained in PSH (phydroxylbenzoic acid; oleic acid; linoleic acid), $\mathrm{C}-\mathrm{H}$ $\left(2,300-2,900 \mathrm{~cm}^{-1}\right), \mathrm{NH}\left(2,360-2,290 \mathrm{~cm}^{-1}\right), \mathrm{C}=\mathrm{O}$ (protonated carboxylic groups or ester groups corresponding to $1,734 \mathrm{~cm}^{-1}$ ), amide $\mathrm{I}$ band is primarily a $\mathrm{C}=\mathrm{O}$ stretching mode centered at $1,641 \mathrm{~cm}^{-1}$, included in the aminoacids and proteins structure (tryptophan, lysine, isoleucine, arginine, asparagines, betaine, and tyrosine). Peak position at 1,441 and $1,425 \mathrm{~cm}^{-1}$ can be attributed to $\mathrm{COO}^{-}$of the carboxylate group, while the band around $1,100-1,000 \mathrm{~cm}^{-1}$ is due to the $\mathrm{C}-\mathrm{O}$ bond characteristic for polysaccharides (lignin, cellulose, hemicelluloses, and pectin). The presence of phosphate and sulfonate groups $(\mathrm{P}-\mathrm{OH}$ or $\mathrm{P}-\mathrm{O}-\mathrm{C}$ stretching and $\mathrm{S}=\mathrm{O}$ ) is indicated by the peaks in the regions $800-850 \mathrm{~cm}^{-1}$.

Erythrosine B may interact with different functional groups from PSH structure. Dye uptake on $\mathrm{PSH}$ is achieved predominantly by ion exchange 
Table 9

Thermodynamic parameters for the sorption of Erythrosine B on PSH

\begin{tabular}{lllll}
\hline & & \multicolumn{2}{l}{ Thermodynamic parameter } \\
\cline { 3 - 4 } Temperature $(\mathrm{K})$ & $K_{\mathrm{L}}(\mathrm{L} / \mathrm{mmol})$ & $\Delta G^{\circ}(\mathrm{kJ} / \mathrm{mol})$ & $\Delta H^{\circ}(\mathrm{kJ} / \mathrm{mol})$ & 67.46 \\
293 & 0.01392 & -21.90 & $\Delta S^{\circ}(\mathrm{J} / \mathrm{mol} \mathrm{K})$ \\
303 & 0.02179 & -24.95 & \\
313 & 0.03423 & -28.00 & & \\
323 & 0.2153 & -31.05 & & \\
\hline
\end{tabular}
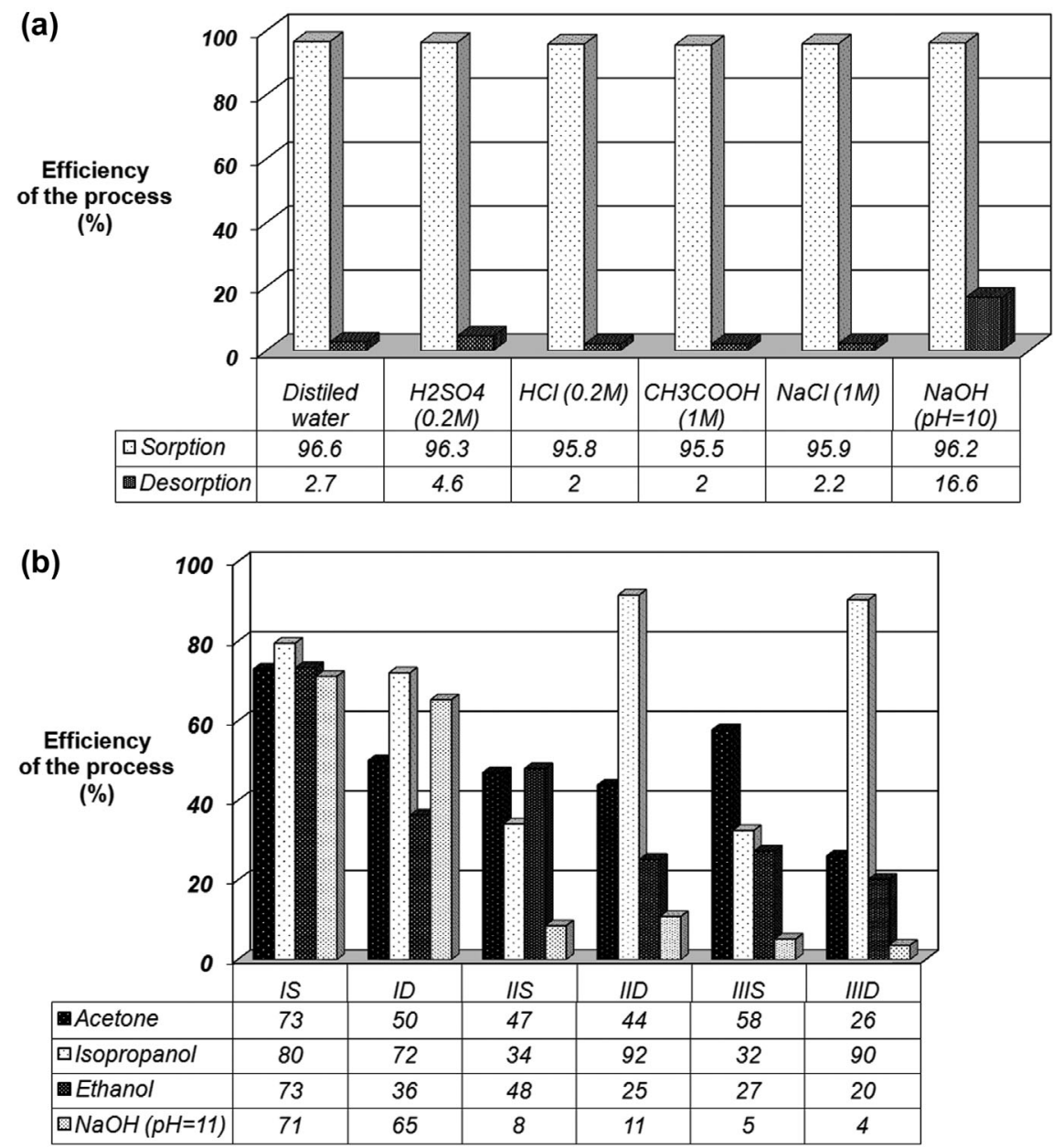

Fig. 17. Desorption efficiency when different solution are used as eluents: (a) one cycle using $\mathrm{H}_{2} \mathrm{O} ; \mathrm{H}_{2} \mathrm{SO}, \mathrm{HCl}_{4}$; $\mathrm{CH}_{3} \mathrm{COOH} ; \mathrm{NaCl}$ and $\mathrm{NaOH}(\mathrm{pH} 10)$ and (b) three cycles using acetone, isopropanol, ethanol and $\mathrm{NaOH}(\mathrm{pH} 11)$.

interactions, the maximum reactive center corresponding to a band at $1,655 \mathrm{~cm}^{-1}$, then $-\mathrm{COO}-\mathrm{Na}^{+}$from the benzene ring without iodine. PSH is involved in Erythrosine $\mathrm{B}$ adsorption process by the band at 1,045.54$1,055 \mathrm{~cm}^{-1}$, corresponding to $\mathrm{C}=\mathrm{O}, \mathrm{C}-\mathrm{O}$ and $\mathrm{C}-\mathrm{N}$ by ion exchange. The others band movement from $\mathrm{PSH}$ spectra after the adsorption process is due to physical interactions (hydrogen bond, van der Waals force) that occur between functional groups of adsorbent and dye.

The attachment of Ery B molecules on adsorbent may be attributed to:

(1) chemical interactions between $\mathrm{COO}-$ or $\mathrm{C}-\mathrm{O}$ groups of the dye and agro-waste wall components, 


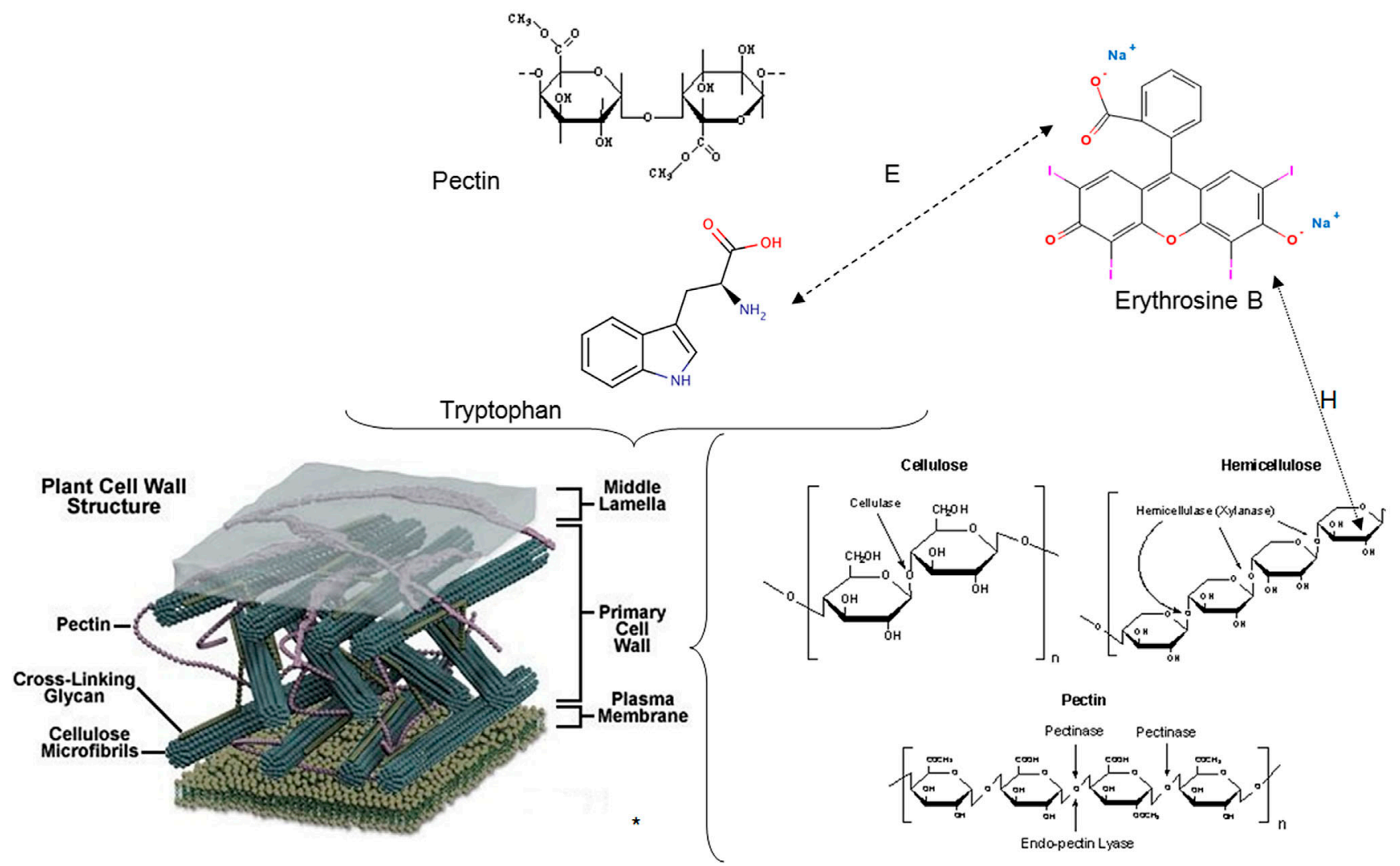

Fig. 18. Interaction between Erythrosine B and agrowaste wall components (Molecular Expressions [67]): E-electrostatic interaction between $\mathrm{COO}^{-}$of Erythrosine $\mathrm{B}$ and $\mathrm{NH}_{2}$ of middle lamella containing protein; $\mathrm{H}-$ hydrogen bonding between hydroxyl groups of the primary and secondary cell wall of the adsorbent and aromatic rings of Erythrosine $\mathrm{B}$.

(2) electrostatic interactions between dye molecules and the electron rich sites on cell surface and,

(3) week physical forces such as hydrogen bonding and van der Waals interaction between the hydrophobic parts of the dye molecule (e.g. aromatic rings) and the polysaccharides of the adsorbent (Fig. 18) as Das et al. [66] proposed for Rhodamine B adsorption on Rhizopus oryzae biomass, respectively.

\section{Conclusions}

(1) The agrowaste PSH can be used as a adsorbent for Erythrosine B removal from aqueous solutions. The amount of adsorbed dye in batch system was found to vary with the initial dye concentration and contact time. Moreover, there are other parameters strongly influencing the process: adsorption is favorable at low acid $\mathrm{pH}$ (5) value, at the optimum adsorbent dosage of $20 \mathrm{~g} / \mathrm{L}$. These interactions were further demonstrated and modeled by factorial design and analysis of experiments, which revealed that there are significant interactions among process factors that affect the Ery B uptake, but a maximum value of uptake was not found in the studied ranges of factors. Therefore, further investigation are necessary to find the optimum values of factors which can determine a maximum Ery B uptake.

(2) Data analysis using kinetic models showed that experimental data are well described by Ho's pseudo-second-order model, suggesting that the adsorption mechanism involves ion exchange and physical interactions. The Erythrosine $B$ adsorption mechanism was predominantly the intraparticle diffusion, but there was also a dependence on pore size as the dye diffuses through different pores (macropores, mesopores, and micropores). The rate of the dye uptake was found to be controlled by the external mass transfer at the 
beginning of the adsorption, while the intraparticle diffusion controlled the overall rate of adsorption at later stages of the process.

(3) The equilibrium data fitted several empirical models (Langmuir, Freundlich, Temkin, and Dubinin-Radushkevich) with a correlation coefficient $R^{2} \geq 0.915$. The maximum adsorption capacity of PSH for Ery B was $16.4 \mathrm{mg} / \mathrm{g}$, at $50^{\circ} \mathrm{C}$. The values of the energy of adsorption $\left(E_{\mathrm{DR}}\right)$ calculated from the Dubinin-Radushkevich isotherm are found to be higher than $9 \mathrm{~kJ} / \mathrm{mol}$. The values of Freundlich constant, $n_{\mathrm{F}}>1$, supports the hypothesis that ion-exchange is the mechanism responsible for a successful adsorption process.

(4) Thermodynamic parameters calculated from the slope and intercept of van't Hoff plots showed negative values of $\Delta G^{\circ}$ which demonstrate that adsorption is highly favorable and spontaneous; positive values of enthalpy change $\left(\Delta H^{\circ}\right)$ signify the endothermic nature of the process. The positive values of $\Delta S^{\circ}$ reveal the affinity of Erythrosine $\mathrm{B}$ for PSH as adsorbent and the phenomena increased disorder while some structural changes in the dye could occur during adsorption.

(5) The desorption studies revealed a higher desorbed percent of dye (17\%) in the case of alkaline water. The adsorbent regeneration has been tested using four solutions. The efficiency of adsorption-desorption process during three cycles was experimented. Isopropanol showed to be the most efficient solvent for Ery B desorption. In the presence of acetone a constant adsorption percentage (around 50\%) for the three adsorption-desoption cycles was achieved.

(6) SEM and FTIR analyses revealed the attachment of Ery B molecules on adsorbent which may be attributed to: (i) chemical interaction between $\mathrm{COO}-$ or $\mathrm{C}-\mathrm{O}$ groups of the dye and agrowaste wall components, (ii) electrostatic interaction between dye molecules and the electron rich sites on cell surface, (iii) week physical force such as hydrogen bonding and Van der Waals interaction between the hydrophobic parts of the dye molecule (e.g. aromatic rings) and the polysaccharides of the adsorbent.

(7) These results demonstrated that PSH is an effective adsorbent for Erythrosine B removal on a wide range of dye concentrations in aqueous solutions (5-400 mg/L) in batch system. Since the agricultural waste used in this study is friendly, abundantly and locally available, the adsorbent is economically viable for aqueous effluents decolorization.

\section{Acknowledgments}

This paper was elaborated with the support of a grant of the Romanian National Authority for Scientific Research, CNCS-UEFISCDI, project number PN-II-ID-PCE-2011-3-0559, Contract 265/2011.

\section{References}

[1] V.K. Gupta, A. Mittal, L. Kurup, J. Mittal, Adsorption of a hazardous dye, erythrosine, over hen feathers, J. Colloid Interface Sci. 304 (2006) 52-57.

[2] A. Mittal, J. Mittal, L. Kurup, A.K. Singh, Process development for the removal and recovery of hazardous dye erythrosine from wastewater by waste materials-Bottom ash and de-oiled soya as adsorbents, J. Hazard. Mater. 138 (2006) 95-105.

[3] F.C. Caliman, L.C. Apostol, L. Bulgariu, D. Bulgariu, M. Gavrilescu, Influence of soil particle size onto sorption of tartrazine from aqueous solutions, Environ. Eng. Manage. J. 8 (2009) 1081-1087.

[4] F.C. Caliman, L.C. Apostol, L. Bulgariu, D. Bulgariu, M. Gavrilescu, Sorption of Acid Yellow 23 from aqueous solutions onto soil, Afinidad 66 (2009) 465-473.

[5] F.C. Caliman, L.C. Apostol, L. Bulgariu, D. Bulgariu, M. Gavrilescu, Study regarding the sorption of erythrosine from aqueous solution onto soil, Environ. Eng. Manage. J. 8 (2009) 1339-1346.

[6] R. Jain, S. Sikarwar, Adsorptive removal of Erythrosine dye onto activated low cost de-oiled mustard, J. Hazard. Mater. 164 (2009) 627-633.

[7] G.J. Jesus, C.R. Corso, A. Campos, S.M.M. Franchetti, Biodegradation of erythrosin $\mathrm{B}$ dye by paramorphic Neurospora crassa 74A, Braz. Arch. Biol. Technol. 53 (2010) 473-480.

[8] L. Pereira, R. Pereira, C.S. Oliveira, L.C. Apostol, M. Gavrilescu, M.N. Pons, O. Zahraa, M.M. Madalena Alves, $\mathrm{UV} / \mathrm{TiO}_{2}$ photocatalytic degradation of xanthene dyes, Photochem. Photobiol. 89 (2013) 33-39.

[9] L.C. Apostol, C. Smaranda, M. Diaconu, M. Gavrilescu, Preliminary ecotoxicological evaluation of Erythrosin B and its photocatalytic degradation products, Environ. Eng. Manage. J. 14 (2015) 465-471.

[10] Green Cotton, Synthetic Dyes: A look at Environmental \& Human Risks, Green Cotton-The Greening of Fashion: One Thread at a Time, 2008. Available from: $<$ https://greencotton.wordpress.com/2008/06/18/syn thetic-dyes-a-look-at-the-good-the-bad-and-the-ugly / > (Accessed August, 2015).

[11] S. Motoc, F. Manea, A. Pop, A. Baciu, G. Burtică, R. Pode, Electrochemical mineralization of Reactive Red 147 Dye on boron-doped diamond electrodes, Environ. Eng. Manage. J. 12 (2013) 509-516.

[12] D. Suteu, G. Biliuta, L. Rusu, S. Coseri, G. Nacu, Cellulose cellets as new type of adsorbent for the removal of dyes from aqueous media, Environ. Eng. Manage. J. 14 (2015) 525-532.

[13] G. Crini, Non-conventional low-cost adsorbents for dye removal: A review, Bioresour. Technol. 97 (2006) 1061-1085.

[14] Y.S. Al-Degs, R. Abu-El-Halawa, S.S. Abu-Alrub, Analyzing adsorption data of erythrosine dye using principal component analysis, Chem. Eng. J. 191 (2012) 185-194. 
[15] L.C. Apostol, F.C. Căliman, M. Gavrilescu, Influence of some parameters on sorption of Erythrosine B onto soil, Bulletin of the Polytechnic Institute from Iaşi, Chem. Chem. Eng. Section LVI (LX) (2010) 47-56.

[16] L.A. Colar, L. Cocheci, E.C. Ilinoiu, F. Manea, C. Orha, R. Pode, Adsorption of RY 125 dye from aqueous solution on a silver doped $\mathrm{TiO}_{2}$ modified clinoptilolite, Environ. Eng. Manage. J. 11 (2012) 1375-1381.

[17] M.C. Alexandrica, M. Silion, D. Hritcu, M.I. Popa, Layered double hydroxides as adsorbents for anionic dye removal from aqueous solutions, Environ. Eng. Manage. J. 14(2) (2015) 381-388.

[18] C. Smaranda, D. Bulgariu, M. Gavrilescu, Equilibrium and kinetic studies of acid dye sorption onto soils from iasi area, Environ. Eng. Manage. J. 9 (2010) 57-66.

[19] L.S. Tan, K. Jain, C.A. Rozaini, Adsorption of textile dye from aqueous solution on pretreated mangrove bark, an agricultural waste: Equilibrium and kinetic studies, J. Appl. Sci. Environ. Sanit. 5 (2010) 283-294.

[20] P. SenthilKumar, R. Gayathri, D.K. Selvaraj, P. Vijayalakshmi, P. RajKumar, J. Nandagopal, S. Sivanesan, Adsorption of dye from aqueous solution using silver wood sawdust carbon, Environ. Eng. Manage. J. 10 (2011) 451-460.

[21] I. Cretescu, M. Diaconu, C. Cojocaru, R.E. Benchea, C. Pohontu, Removal of dunkel blau dye from aqueous solutions by fungal and peat biomass in batch mode, Environ. Eng. Manage. J 9 (2010) 107-112.

[22] M.R. Samarghandi, M. Zarrabi, A. Amrane, M.M. Soori, M.M. Sepehr, Removal of Acid Black Dye by pumice stone as a low cost adsorbent: Kinetic, thermodynamic and equilibrium studies, Environ. Eng. Manage. J. 12 (2013) 2137-2147.

[23] R. Jain, M. Bhargave, N. Sharma, Electrochemical degradation of erythrosine in pharmaceuticals and food product industrial effluent, J. Sci. Ind. Res. 64 (2005) 191-197.

[24] M.A. Hasnat, M.M. Uddin, A.J.F. Samed, S.S. Alam, S. Hossain, Adsorption and photocatalytic decolorization of a synthetic dye erythrosine on anatase $\mathrm{TiO}_{2}$ and ZnO surfaces, J. Hazard. Mater. 147 (2007) 471-477.

[25] R. Jain, S. Sikarwar, Semiconductor-mediated photocatalyzed degradation of erythrosine dye from wastewater using $\mathrm{TiO}_{2}$ catalyst, Environ. Technol. 31 (2010) 1403-1410.

[26] I. Dahlan, A.S.M. Noor, Study on the removal characteristic of acid violet dye from synthetic wastewater using a novel RHA/PFA/CFA sorbent, Environ. Eng. Manage. J. 13 (2014) 197-204.

[27] L. Wright, B. Boundy, P.C. Badger, B. Perlack, D. Stacy, Biomass Energy Data Book, fourth ed., US Department of Energy, Oak Ridge, Office of the Biomass Program Energy Efficiency and Renewable Energy, 2011.

[28] A. Elaziouti, N. Laouedj, B. Ahmed, ZnO-assisted photocatalytic degradation of Congo Red and Benzopurpurine $4 \mathrm{~B}$ in aqueous solution, J. Chem. Eng. Process Technol. 2 (2011) 1-9.

[29] N. Fiol, I. Villaescusa, Determination of sorbent point zero charge: Usefulness in sorption studies, Environ. Chem. Lett. 7 (2008) 79-84.
[30] K. Bourikas, J. Vakros, C. Kordulis, A. Lycourghiotis, Potentiometric mass titrations: Experimental and theoretical establishment of a new technique for determining the point of zero charge (PZC) for metal (hydr) oxides, J. Phys. Chem. B 107 (2003) 9441-9451.

[31] L.C. Brown, P. Mac Berthouex, Statistics for Environmental Engineers, second ed., CRC Press, Boca Raton (2002).

[32] Y.S. Aldegs, M.I. Elbarghouthi, A.H. Elsheikh, G.M. Walker, Effect of solution $\mathrm{pH}$, ionic strength, and temperature on adsorption behavior of reactive dyes on activated carbon, Dyes Pigm. 77 (2008) 16-23.

[33] M. Colombini, C.Y. Wu, A food dye, erythrosine B, increases membrane permeability to calcium and other ions, Biochim. Biophys. Acta (BBA)-Biomembranes 648 (1981) 49-54.

[34] S.S. Moghaddam, M.R. Alavi Moghaddam, M. Arami, Decolorization of an acidic dye from synthetic wastewater by sludge of water treatment plant, Iran. J. Environ. Health Sci. Eng. 7 (2010) 437-442.

[35] V. Jaikumar, K. Sathish Kumar, D. Gnana Prakash, Sorption of acid dyes using spent brewery grains: Characterization and modeling, Int. J. Appl. Sci. Eng. 7 (2009) 115-125.

[36] X. Pan, D. Zhang, Removal of Malachite Green from water by Firmiana simplex wood fiber, Electron. J. Biotechnol. 12 (2009) 1-10.

[37] R. Ansari, Z. Mosayebzadeh, Removal of Eosin Y, an anionic dye, from aqueous solutions using conducting electroactive polymers, Iran. Polym. J. 19 (2010) 541-551.

[38] R.M. Dhoble, S. Lunge, A.G. Bhole, S. Rayalu, Magnetic binary oxide particles (MBOP): A promising adsorbent for removal of As (III) in water, Water Res. 45(16) (2011) 4769-4781.

[39] M. Malakootian, M. Moosazadeh, N. Yousefi, A. Fatehizadeh, Fluoride removal from aqueous solution by pumice: Case study on Kuhbonan Water, Afr. J. Environ. Sci. Technol. 5 (2011) 299-306.

[40] M. Wawrzkiewicz, Z. Hubicki, Equilibrium and kinetic studies on the sorption of acidic dye by macroporous anion exchanger, Biochem. Eng. J. 157 (2010) 29-34.

[41] S. Akhnazarova, V. Kafarov, Experiment Optimization in Chemistry and Chemical Engineering, Mir Publisher, Moscow, 1982.

[42] SPC EXCEL, Box-Cox and Johnson Transformations, Available from: <https://www.spcforexcel.com/spcfor-excel/box-cox-transformation $>$.

[43] S. Banerjee, M.C. Uma Chattopadhyaya, Y.C. Sharma, Fast and economically viable removal of a cationic dye from aqueous solutions: Kinetic and equilibrium modeling, Environ. Eng. Manage. J. 12 (2013) 2183-2190.

[44] K.Y. Foo, B.H. Hameed, Insights into the modeling of adsorption isotherm systems, Chem. Eng. J. 156 (2010) 2-10.

[45] R. Ahmad, Studies on adsorption of crystal violet dye from aqueous solution onto coniferous pinus bark powder (CPBP), J. Hazard. Mater. 171 (2009) 767-773.

[46] S.D. Khattri, M.K. Singh, Removal of malachite green from dye wastewater using neem sawdust by adsorption, J. Hazard. Mater. 167 (2009) 1089-1094. 
[47] A.N. Oladoja, C.O. Aboluwoye, Y.B. Oladimeji, Kinetics and isotherm studies on methylene blue adsorption onto ground palm kernel coat, Turkish J. Eng. Environ. Sci. 32 (2008) 303-312.

[48] T.V.N. Padmesh, K. Vijayaraghavan, G. Sekaran, M. Velan, Application of two- and three-parameter isotherm models: Sorption of Acid Red 88 onto Azolla microphylla, Biorem. J. 10 (2006) 37-44.

[49] Y.S. Ho, G. Mckay, Kinetic models for the sorption of dye from aqueous solution by wood, Process Saf. Environ. Protect. 76 (1998) 183-191.

[50] S. Patil, V. Deshmukh, S. Renukdas, N. Patel, Kinetics of Adsorption of Crystal Violet from aqueous solutions using different natural materials, Int. J. Environ. Sci. 1 (2011) 1116-1134.

[51] B.H. Hameed, M.I. El-Khaiary, Removal of basic dye from aqueous medium using a novel agricultural waste material: Pumpkin seed hull, J. Hazard. Mater. 155 (2008) 601-609.

[52] M. Arami, N.Y. Limaee, N.M. Mahmoodi, Evaluation of the adsorption kinetics and equilibrium for the potential removal of acid dyes using a biosorbent, Chem. Eng. J. 139 (2008) 2-10.

[53] B.K. Nandi, A. Goswami, M.K. Purkait, Adsorption characteristics of brilliant green dye on kaolin, J. Hazard. Mater. 161 (2009) 387-395.

[54] V.K. Gupta, Suhas, Application of low-cost adsorbents for dye removal-A review, J. Environ. Manage. 90 (2009) 2313-2342.

[55] A.U. Itodo, H.U. Itodo, Utilizing D-R and Temkin Isotherms with GCMS external standard technique in forecasting liquid phase herbicide sorption energies, EJEAFChe. 9 (2010) 1792-1802.

[56] N.T. Abdel-Ghani, M.M. Hefny, G.A. El-Chaghaby, Removal of metal ions from synthetic wastewater by adsorption onto Eucalyptus camaldulenis tree leaves, J. Chil. Chem. Soc. 53 (2008) 1585-1587.

[57] R. Klimaviciute, J. Bendoraitiene, R. Rutkaite, A. Zemaitaitis, Adsorption of hexavalent chromium on cationic cross-linked starches of different botanic origins, J. Hazard. Mater. 181 (2010) 624-632.
[58] S.M. de Oliveira Brito, H.M. Carvalho Brito, L.F. Soares, R.P. de Azevedo, Brazil nut shells as a new biosorbent to remove Methylene Blue and Indigo Carmine from aqueous solutions, J. Hazard. Mater. 174 (2010) 84-92.

[59] C.T. Hsieh, H. Teng, Langmuir and DubininRadushkevich analyses on equilibrium adsorption of activated carbon fabrics in aqueous solutions, J. Chem. Technol. Biotechnol. 75 (1980) 1066-1072.

[60] F. Deniz, S.D. Saygideger, Equilibrium, kinetic and thermodynamic studies of Acid Orange 52 dye sorption by Paulownia tomentosa Steud. leaf powder as low-cost natural biosorbents, Bioresour. Technol. 101 (2010) 5137-5143.

[61] F.C. Caliman, M. Gavrilescu, Sorption of cationic dyes from aqueous solution onto natural clay. Equilibrium and kinetic study, Environ. Eng. Manage. J. 7 (2008) 301-308.

[62] J. Wu, H.O. Yu, Biosorption of 2,4-dichlorophenol from aqueous solution by Phanerochaete chrysosporium biomass: Isotherms, kinetics and thermodynamics, J. Hazard. Mater. 137 (2006) 498-508.

[63] W.H. Cheung, Y.S. Szeto, G. McKay, Intraparticle diffusion processes during acid dye adsorption onto chitosan, Bioresour. Technol. 98 (2007) 2897-2904.

[64] M. Hema, S. Arivoli, Comparative study on the adsorption kinetics and thermodynamics of dyes onto acid activated low cost carbon, Int. J. Phys. Sci. 2 (2007) 10-17.

[65] R.A. Al-Bayati, Adsorption-desorption isotherm of one of antidiabetic drug from aqueous solutions on some pharmaceutical adsorbents, Eur. J. Sci. Res. 40 (2010) 580-588.

[66] S.K. Das, J. Bhowal, A.R. Das, A.K. Guha, Adsorption behavior of Rhodamine B on Rhizopus oryzae biomass, Langmuir 22 (2006) 7265-7272.

[67] Molecular Expressions, Plant Cell Wall Structure, (2011). Available from: <http://micro.magnet.fsu. edu/cells/plants/cellwall.html> (August, 2015). 